
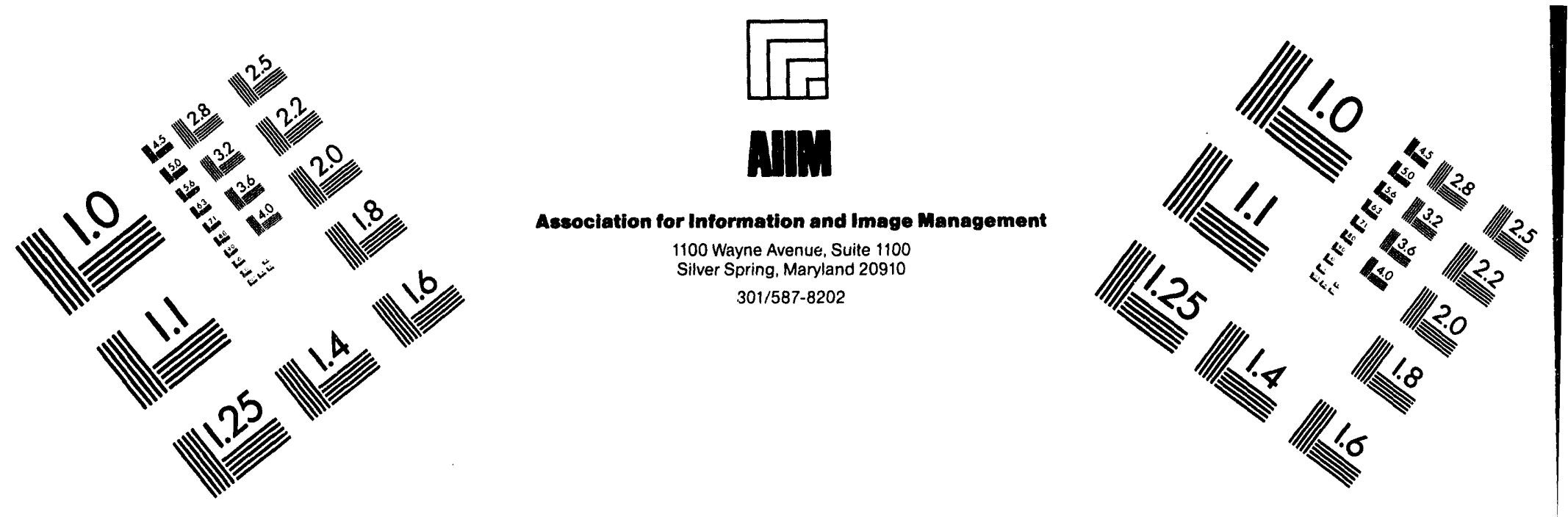

\title{
Centimeter
}

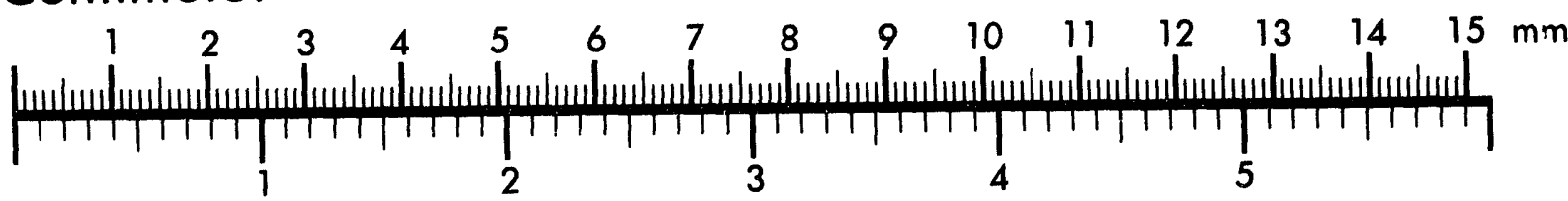
Inches
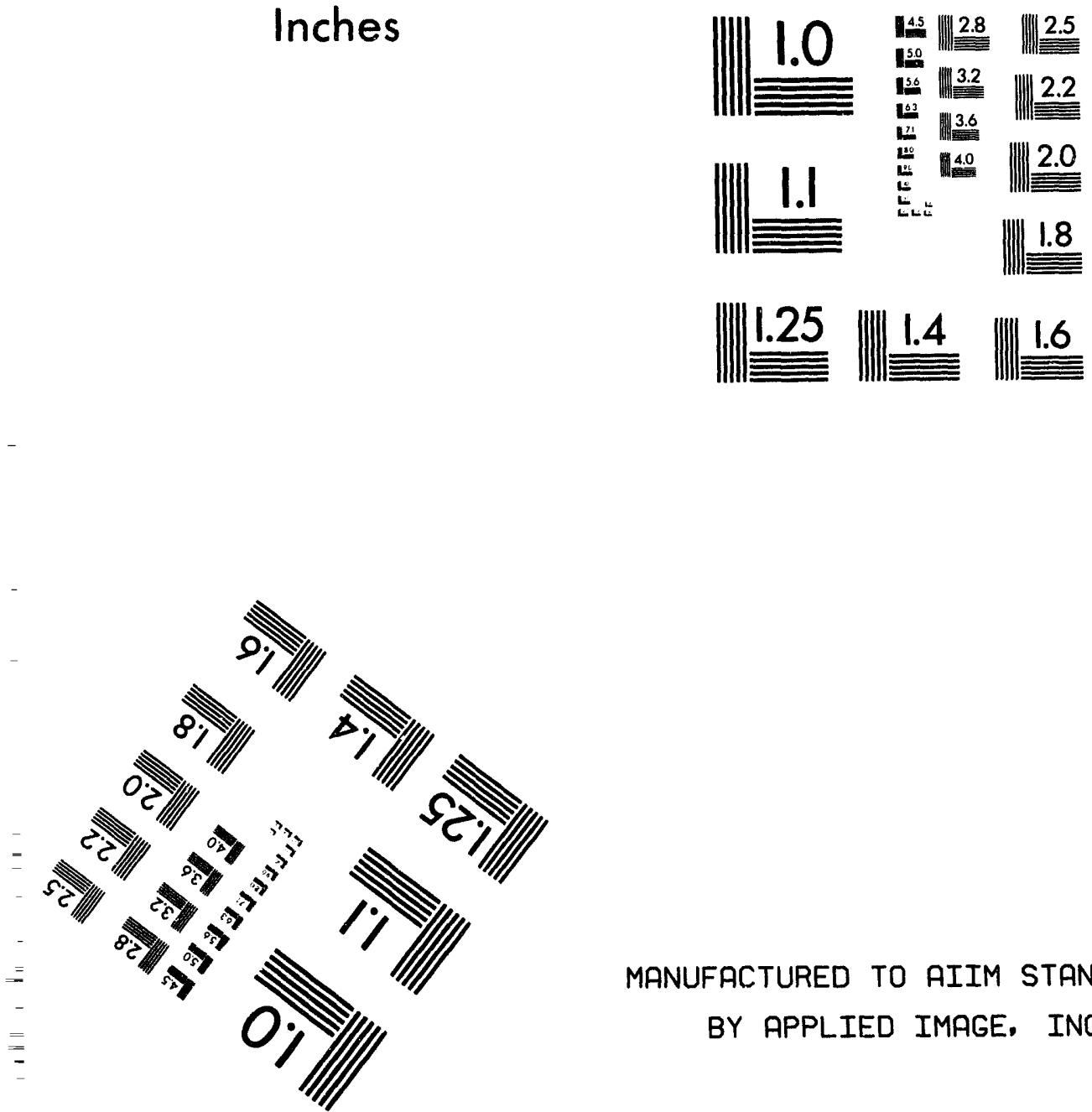

MANUFACTURED TO AIIM STANDARDS

BY APPLIED IMAGE. INC.

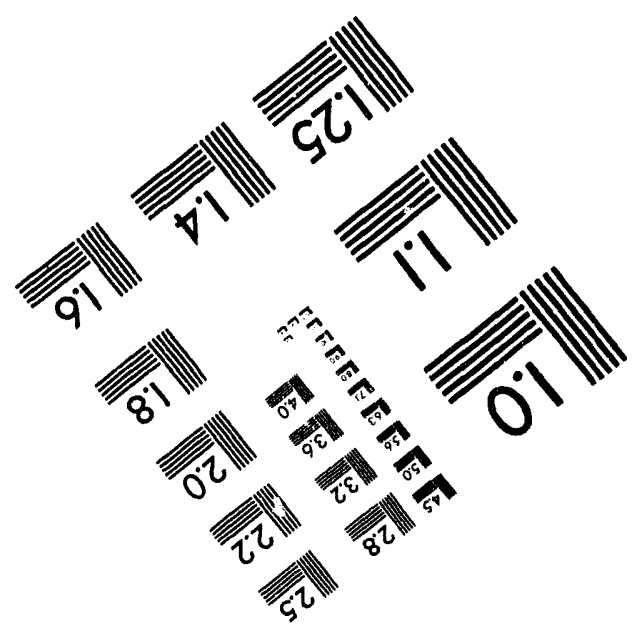



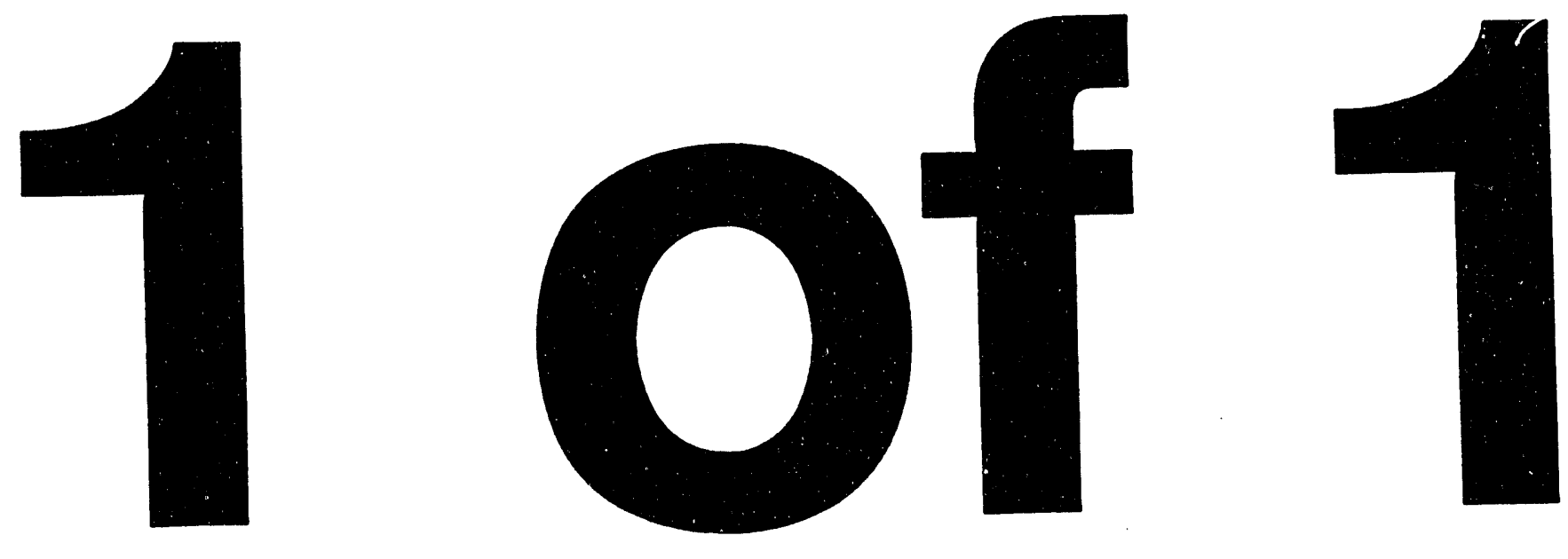


\section{DELPHI \\ AN INTRODUCTION TO OUTPUT LAYOUT AND DATA CONTENT}

C.F. Smith

August 16, 1994

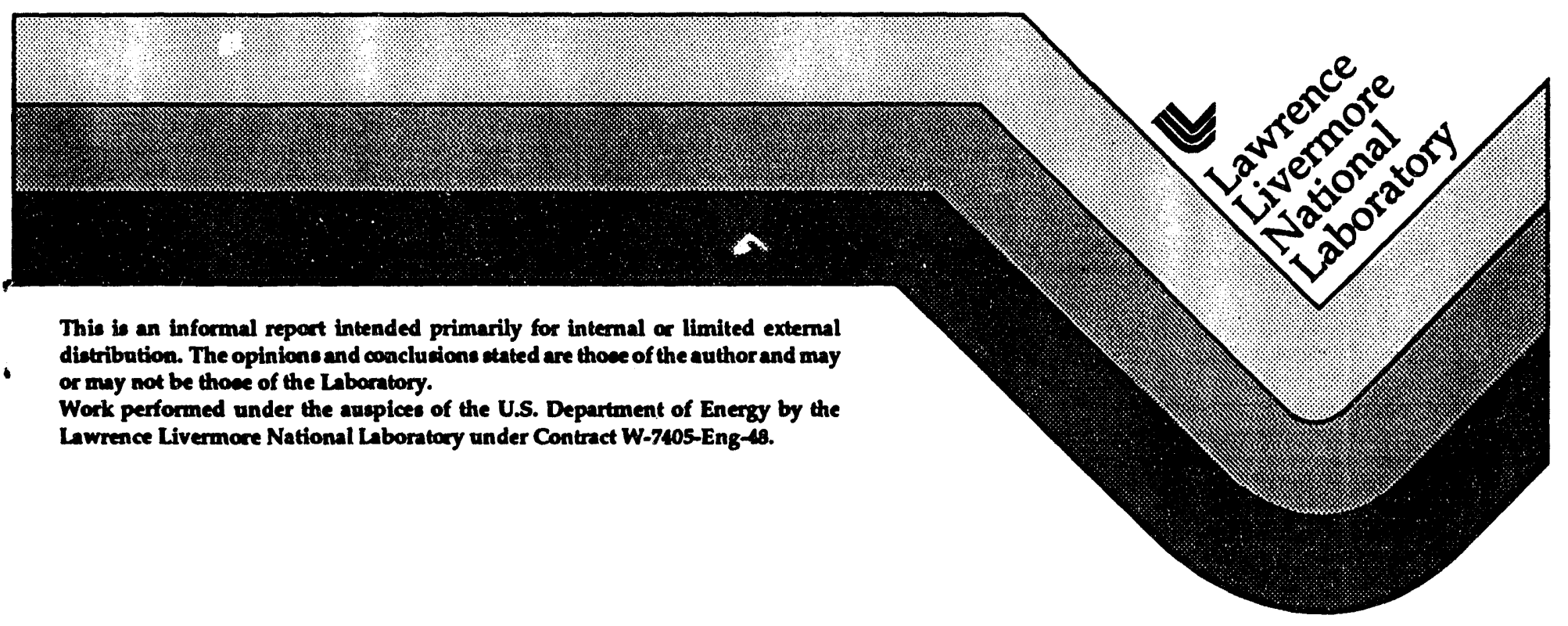




\section{DISCLAIMER}

This document was prepared as an account of work sponsored by an agency of the United States Government. Neither the United States Government nor the University of California nor any of their employees, makes any warranty, express or implied, or assumes any legal liability or responsibility for the accuracy, completeness, or usefulness of any information, apparatus, product, or process disclosed, or represents that its use would not infringe privately owned rights. Reference herein to any specific commercial products, process, or service by trade name, tradernark, manufacturer, or otherwise, does not necessarily constitute or imply its endorsement, recommendation, or favoring by the United States Government or the University of California. The views and opinions of authors expressed herein do not necessarily state or reflect those of the United States Government or the University of California, and shall not be used for advertising or product endorsement purposes.

This report has been reproduced directly from the best available copy.

Available to DOE and DOE contractors from the Office of Scientific and Technical Information

P.O. Box 62, Oak Ridge, TN 37831

Prices available from (615) 576-8401, FTS 626-8401

A vailable to the public from the

National Technical Information Service

US. Department of Commerce

5285 Port Royal Rd.

Springfield, VA 22161 
DELPHI

\title{
AN INIRODUCTION TO OUTPUT IAYOUT AND DATA CONIENT
}

\author{
C. F. Smith
}

$$
8 / 16 / 94
$$

DELPHI was the data summary and interpretation code used by gas diagnostics personnel during the period from 1968 through 1986. It was written by Floyd Momyer, and went through several revisions during its period of use. Described here is the final version, which provided the most extensive set of summary tables. Earlier versions of the code lacked some of the capabilities of the final version, but what they did include was of substantially the same format. DELPHI was run against most available input decks in the mid 1980s. Microfiche and hardoopy output were generated. Both now reside in our archives. These reruns used modified input decks, which may not have had the proper "trigger" to instruct DELPHI to output some tables. These tables could, therefore be missing from a printout even though the necessary data was present. Also, modifications to DELPHI did, in some instances, eliminate DELPHI' capability to correctly output some of the earlier optional tables. This monologue is intended to compliment the archived printout, and to provide enough insight so that someone unfamiliar with the techniques of Gas Diagnostics can retrieve the results at some future date.

DELPHI last ran on the CDC-7600 machines, and was not converted to run on the Crays when the CDC-7600's were desormissioned. DETPHJ. accepted data from various analytical systems, set up data summary tables, and combined preshot tracer and detector data with these results to calculate the total production of measured species and the indicated fission yields and detector conversions.

The DELPHI code, itself, was treated as Secret Restricted Data, as was the printed output. Neither the code nor the output were documented. Instead we "agreed" to carefully label and protect them as SRD throughout our operations. This "agreement" was reached because of the continual coding revisions and/or additions of new data followed by the creation of updated printouts. These transitory conditions no longer are applicable. The DELPHI code and printout have become one of a kind historical archives of the techniques and experimental results of the early Gas Diagnostics effort. As such they fall under the DOE directive for documentation and retention.

Input to DELPHI consisted of a series of card images of various types. Each type pertains to a specific class of information. The card deck was not considered classified, as it had no clear text descriptors, used code numbers to identify species and events, and the numbers were unitless. These card decks have been retained, although their usefulness after the passage of time is questionable. 


\section{Summary of the Printout contents}

The entire input deck was listed on the initial pages of DETPHI output. No data manipulation was done prior to this listing. The imput file was not constructed to facilitate data interpretation. It was used to facilitate input card format checks, to verify the completeness of the input deck, and to locate any imput errors.

Following the input file list are two special purpose data summaries. The first is a summary of the gaseous tracer and detector species. Quantities of those materials, which were loaded prior to device emplacement, are given by isotope in units of mole fraction, liters (STP), and atoms. The second table is a summary of analytical results for any pre-shot samples obtained. These two tables appear only once in the output pages.

The main body of output by DELPHI is modular. Each module contains a sequence of data tables calculated using one of the tracer gases as the device fraction indicator. There is a module for each tracer gas. The tables in different modules differ only when the entries are calculated using the particular tracer species for that module. Thus, input tables for all modules are identical. DELPHI could summarize results from no more than 10 samples at a time. If more than 10 samples were analyzed, a separate input deck was required. output modules for the additional data appear after all modules for the first deck are printed. There was no coding to create a combined summary of all data. Normally we restricted input to 10 or fewer samples by judicious selection of samples for processing or by replacing results from poor samples with data for higher quality samples when they became available.

Data tables appearing in sequence in each module are identified below. (Note: table numbers are used in this summary only for reference. They do not appear in the DEIPHI printout.)

1. Radiochemical Results. Input data (atoms at event zero time per liter STP of sample gas) is presented by sample number for all radionuclides measured and for certain stable fission product gases. Up to five entries for a given isotope and sample are allowed, each representing a distinct measurement system.

2. Total Atoms. Concentration data converted to total atoms based on the indicated tracer species. Format similar to table 1. 
3. Atoms per Fission. This table contains the measured device atoms per fission for the device. It is calculated using the measured total atoms for krypton and xenon fission products and a total number of device fissions input to the code. This table is not part of the routine output. It appears only when a total fissions card is present.

4. Fission Split. A listing of fission gas " $Q$ " values (atoms produced per fission of the specified type relative to atoms produced per U-235 thermal neutron induced fission) for each fissile material and neutron energy specified in the imput. These are combined using specified weight factors to obtain a "Q" value for the device, and with U-235 thermal atam yields to obtain device atoms per fission.

5. Fission Yield (chain). Indicated fission yield (Kt) assuming complete chain ingrowth for most fission product gases tabulated in table 2. This table begins on the same page as table 3. Format similar to table 1.

6. Fission yield (Independent). Indicated fission yield (Kt) assuming the presence in the gas of only the independent yield of the fission product xenons. Format similar to table 1.

7. Detector Data and Results. Data relevant to the detector species and a listing of the atom loadings head this table. Measured product species are listed by sample number and source. Data is presented as fractional conversion of the load as represented by the total atoms of the product species given in table 2. Each detector species and the associated conversion data is summarized in turn on consecutive pages. These tables are present in the DEIPHI output only if a detector load was specified in the input file.

8. Mass Spec Data. Input data table for Mass Spectrometry results. Each constituent is summarized by sample number as its mole fraction in the gas sample as collected. Up to five entries are possible for each constituent representing different sample containers, mass spectrometers and analysis techniques.

9. Selected Mass Spec Data. A subset of the data in table 8. Specified input data are summarized one entry per constituent.

10. Renormalized Mass spec Data. Mole fraction data as in table 9, but with the major constituents renormalized to sum to unity.

11. Totals of Chemical Species. Data from table 10, converted to total liters (STP) of the constituents based on the specified tracer gas. 
12. Normal Air Free Concentrations. Mole fractions of constituents after the components of normal air based on oxygen have been subtracted. Renormalized to sum to unity.

13. Totals of Chemical Species After Oxygen Air Subtraction. Data from table 12 converted to total liters (STP) of the constituents based on the specified tracer gas.

14. Argon-Air-Free Concentrations. Mole fractions of constituents after the components of additional oxygen free air based on argon have been subtracted. Renormalized to sum to unity.

15. Totals of Chemical Species After Argon Air Subtraction. Data from table 14 converted to total liters (STP) of the constituents based on the specified tracer gas.

16. Totals of Constituents - Summary Tables. These are a series of tables individually summarizing the cotal amount measured, the amount contributed by normal air, by oxygen free air and attributed to device residual cavity gas for each constituent of the sample. Both argon and neon are used to indicate the oxygen free air component. Device residuals are tabulated in units of total liters, moles, and fraction of the original sample constituent.

17. DPM per liter table. Disintegrations per minute per liter of sample after subtraction of normal air based on oxygen. This was a common reporting base for Plowshare gas stimulation experiments.

18. picocuries per milliliter. Radionuclide concentrations from table 17 expressed as $\mathrm{pCi} / \mathrm{ml}$ (also after subtraction of normal air based on Oxygen).

19. Specific Activities table. DPM per liter of isotopic species. This table was useful in evaluating dilution effects, exchange reactions and differential fractionation effects. It was of particular value in Gas Stimulation experiments (Plowshare Program)

20. Total Tritium Results. Summary of input data and calculations of total residual tritium based on loaded D2O tracer. This is a single table in recent printouts, and is several tables in older printouts where the background $\mathrm{D} / \mathrm{H}$ ratio was iterated to obtain optimum agreement between determinations based on several samples. 
II. CONVENITONS FOR DELPHI OUTPUT TABIES:

SAMPLE IDENTIFICATION:

Samples are identified by pot Number. This number usually increases in onder of sample collection.

Sample Source Key is $X . Y Y Y$ where $X$ is a sampling conduit and YYY is the length of the conduit in tens of feet. Typically $X=1$ for the prompt sampling hose and $X=2$ for post-shot re-entry drilliback sampling. Additional key numbers are assigned for grab, second drillback or other nonstandard sources. Consult the sample log.

Sampling Time is given as elapsed days between collection and the event zero time. Entries are to the nearest 0.001 day $(1.4 \mathrm{~min}$.$) .$

DATA TABULATIONS:

Radionuclide and stable fission product concentrations are usually listed in units of atoms at event zero time per liter (STP) of sample cjus. In early (pre 1972) versions of DEIPHI, fission product species (including $\mathrm{Kr}-85$ tracer loads) were listed as Oralloy thermal fissions.* Non-fission, radioactive species were listed as disintegrations per minute per liter (STP) (dpm/l) in these early versions. Up to five measurement sources could be entered. These include thin window and internal proportional beta counting and gamma spectrometry of separated fractions of the sample, gamma spectrometry of an aliquant of unprocessed sample and mass spectrometry. Stable isotopes contributed from air or tracer gas as well as fission are reported as excess (i.e. corrected for these contributions).

CAUIION: Beta counting results are not corrected for precursor decay. Gamma counting results are corrected for decay of metastable states but only if the precursor is measured in the counting sample.

* The term "Oralloy thermal fissions" refers to the number of thermal neutron induced fissions of U-235 required to produce the amount of the species measured or loaded. It is shortened in the DEIPHI printout to "OY TH F". The symbol Oy is used for the U-235 (Oralloy) produced by Oak Ridge during the Manhattan Project. 
Chemical constituents are tabulated as mole fractions. Up to five measurement sources could be entered. These are chemical composition data from two sample cylinders and three sets of rare gas concentrations from two analytical techniques used to determine the species in the two cylinders. Tracer neon-22 is reported as XsNe22 and is the excess of that isotope present above that from air.

Errors of all measurements are tabulated as percent standard deviations of the mean of replicate determinations. Errors of average values determined by DEI PHI are percent standard deviations of a measurement.

Identification of species is by the chemical symbol if the data entry refers to an element, and by the key ZZAAA for entries referring to an isotope. $(\mathrm{ZZ}=$ Atomic Number; $\mathrm{AAA}=$ Atomic Weight). Special values of AAA are used to identify metastable isomers ( $A A A=A A A+300)$, mass spectrometric determinations $(A A A=5 A A)$ and more than one equivalent determination (i.e. two mass spectrometric determinations of an isotope could be ZZOAA and ZZ1AA).

\section{Radionuclide Measurement Keys}

Radionuclide measurement key numbers are used to indicate the measurement system used to obtain the concentration data. The measurement keys are listed memonically in DEIPHI. Early versions of DELPHI did not have this indicator. The Keys and their expanded meanings are:

$1=\mathrm{BETA}$

$2=$ LOBACA

3=SEP GEII

4=GROSS GELI

5=MASS SPEC
Thin window beta proportional counting of a separated fraction of the sample gas.

Internal beta proportional counting of a separated fraction of the sample gas.

Ganma spectrometric determination using a separated fraction of the sample gas.

Gamma spectrometric determination using an aliquant of unprocessed sample gas.

Isotopic measurements made by mass spectrometry regardless of instrument or technique. 


\section{GUIDES TO THE SELECTION OF THE "BEST" RADIOCHEMICAL DATA}

\section{INITERFERENCFS:}

1. Krypton-85 is not well determined by ganma spectrometry if Krypton-79 is present due to interference between the $\mathrm{Kr}-85513 \mathrm{keV}$ gamma ray and the $\mathrm{Kr}-79510 \mathrm{keV}$ positron annihilation radiation.

2. Xenon-133 is not well determined by gamma spectrometry in early samples due to it's relatively low activity level and the presence of high compton signals covering it's low energy (80 keV) ganma radiation.

\section{SEIECIION CRITERTA:}

$\mathrm{Kr}-85$ Key 1=BETA is the measurement of choice. In good quality samples from a predominately fission device the Key 5=MASS SPEC values are also good. At late times Key 3=SEP GELI may be satisfactory.

$\mathrm{Kr}-85 \mathrm{~m}$ Key $4=$ GROSS GELI is usually the method of choice. If $\mathrm{Kr}-88$ separations are completed early enough, the Key $3=$ SEP GEII may $\mathrm{Kr}-87$ be preferable. Rarely are Key l=BETA decay curves resolved Xe-135 well enough to give reliable determinations.

$\mathrm{Kr}-79$ Key 3-SEP GELI is the method of choice. Xe-133m may be $\mathrm{Xe}-133 \mathrm{~m}$ adequately determined in late Key $4=$ GROSS GEII Xe-131m counts. The others not so in general.

Xe-133g Key 1=BETA is the measurement of choice. Late gamma spectrometric measurements may be acceptable (either Key 3=SEP GEII, or Key $4=$ GROSS GETI). If Xe-133m is measured in a gamma spectrum, the Xe-133g is corrected for the isomer decay back to event zero time. No correction is applied if the count is too late to observe Xe-133m, and no correction is applied for beta decay measurements.

$\mathrm{Kr}-86$ Key $5=$ MASS SPEC is the only measurement for stable species.

$\mathrm{Xe}-136$

$\mathrm{Xe}-134$

$\mathrm{Kr}-77$ Key $4=$ GROSS GEII is the only reliable measurement. Counts are Xe-123 made using a field filled high pressure counting cell.

Br-77 Key 4=GROSS GEII is the only reliable measurement. counts are I-123 made on evacuated high pressure field cells after precursor decay. $\mathrm{Br}-76$ and $\mathrm{I}-122$ can also be measured in the empty cells. 
$\mathrm{Kr}-76$ Key 3=SEP GELI is the measurement of choice.

$\mathrm{Br}-76$

$\mathrm{Xe}-122$

$\mathrm{I}-122$

\section{GUIDES:}

Look at errors. Discount data with larger than normal errors. Look at totals and averages. Discount data with erratic totals. Look at all measurement sources. Discount widely disparate data.

\section{Sample Cylinder and Mass Spectrometry Source Keys}

Mass Spectrometric concentration data could be entered for three analytical techniques and two cylinder sizes. Typically, during prompt sampling operations, both a $1500 \mathrm{c}$ and a $250 \mathrm{c}$ sample cylinder were present at each sample port. These were referred to in the printout as "BIG" and "SMALL", respectively.

Samples taken by other than prompt sampling techniques (late time, grab, drill hole tubing, etc.) were always identified as "BIG". These were generally of at least 10 liters (STP) in volume, and could be collected in a variety of cylinder sizes and configurations. No "SMALL" cylinders were obtained in these samplings.

The principal analytical technique for determination of gross chemical composition of the samples was referred to as Analytical Mass Spectrometry (AMS), and was developed and operated by the chemistry and Materials science Department. The technique provided gross composition measurements for both "BIG" and "SMALL" samples throughout the history of Gas Diagnostics. AMS was also the principal measurement technique for the noble gases in the early years, and continued to be used routinely until the mid 1980s when separated isotopic tracers became available. This technique was limited to "BIG" sample cylinders because of the volume of gas required.

In the late 1970s, the nuclear Chemistry Division built and began operating a high-sensitivity, high-precision stable-isotope gas mass spectrometer system for determination of the noble gas concentrations. The system could provide noble gas concentrations and isotope ratios for both the "BIG" and "SMALL" sample cylinders.

Sample Cylinder and Mass Spectrometric Source Keys used by DELFHI are identified mnemonically in the printout (Tables 8. through 16.). Expanded definitions are as follows: 


\begin{tabular}{|c|c|c|}
\hline \multirow[t]{5}{*}{ Source } & $1=I D M S B I G$ & $\begin{array}{l}\text { Isotope Dilution Mass Spectrometry to } \\
\text { determine the rare gas concentrations } \\
\text { using the langer cylinder as the gas } \\
\text { source. }\end{array}$ \\
\hline & 2=IDMSSMALL & $\begin{array}{l}\text { Isotope Dilution Mass Spectrametry to } \\
\text { determine the rare gas concentrations } \\
\text { using the smaller cylinder as the gas } \\
\text { source. }\end{array}$ \\
\hline & $3=A M S B I G$ & $\begin{array}{l}\text { Analytical Mass Spectrometric analysis on } \\
\text { gettered rare gas fractions of one liter } \\
\text { aliquants of the sample to determine rare } \\
\text { gas concentrations. (Sometimes used } \\
\text { interchangeably with Source Key } \\
5=\text { GROSSBIG). }\end{array}$ \\
\hline & $4=$ GRSSMAIL & $\begin{array}{l}\text { Analytical Mass Spectrometry to determine } \\
\text { concentrations of major gaseous } \\
\text { constituents using the smaller cylinder as } \\
\text { the gas source. }\end{array}$ \\
\hline & $5=$ GROSSBIG & $\begin{array}{l}\text { Analytical Mass spectrometry to determine } \\
\text { concentrations of major gaseous } \\
\text { constituents using the larger cylinder as } \\
\text { the gas source. }\end{array}$ \\
\hline
\end{tabular}

VI. GUIDES TO THE SELECTION CF THE "BEST" CHEMICAL COMPOSIIION DATA

In practically all cases, the measurements of choice are those for the "BIG" cylinder. Analyses of the "SMALL" cylinder were usually used to normalize unique components (typically short lived radionuclides) of the sample to correspond to components in the "BIG" cylinder. These normalized data were then simply appended to the "BIG" cylinder analyses to fill-out the list of measurements in table 1 .

Adoption of the "BIG" cylinder as the sample of choice was made for at least three reasons. First, AMS rare gas analysis could only be performed using the "BIG" cylinder sample due to gas volume requirements. Second, separation chemistry was typically only performed on the "BIG" sample (the "SMALL" sample was usually only gross counted to determine concentrations of short lived fission product gases). Third, the "BIG" sample remaining after the initial aliquanting was retained as an historic archival which permitted re-analysis, if necessary, to resolve problems of agreement with other data or to provide results for additional species. (Many of these archived samples remain in storage today.) 
Chemical camposition data came, in most instances, from Aus. Hence the analysis key 5 = GROSSEIG is the usual preference. Analyses were normally run in duplicate and the quoter. uncertainties are the standard deviation of a measurement based on the agreement between replicates. DWIPII did not allow less than $0.5 \%$ errors for the AMs measurements, however, as this technique was not considered to be capable of higher accuracy.

The reliability of AMS identification and quantification was usually ciuite good. There were two problems of note. First, the determination of small quantities of $\infty$ in the presence of $\mathrm{N}_{2}$ was questionable. We usually added the two together when the $\infty$ was a few percent (or less) in the sample. Second, the identification routine for the AMS analysis nearly always included several light hydrocarbon gases as sample components. In many cases replication was poor, and the presence of these species was questioned. Generally, only Ethane and Propane were included in the tables as components. Other species reported were added together and listed in the tables as a component named "GUNK".

The preponderance of noble gas analyses were performed on gettered sample gas by AMS (analysis key $3=$ AuSBIG). The AMS analyses were usually run in triplicate on a single aliquant. Agreement between analytical replicates is represented by the percent standard deviation of a measurement given in table 8. AMS was quite good for the major noble gases $\mathrm{He}, \mathrm{Ne}$, and $\mathrm{Kr}$ ) and acoeptably good for Xe. (Ar came from the gross analyses) In the absence of fractionation, we generally preferred the $\mathrm{Kr}$ tracer measurements to the Xe measurements because of the higher precision of the results.

For a brief period, the NCD isotope dilution measurement capability provided improved measurement capability. In most, if not all, of these cases both techniques were used to measure noble gas concentrations, and it was normal to include the two sets of data in the tables for direct complarison. Two versions of DELPFI were printed - one for IDMS and the other for AMS. Generally, when facing this choice, IDMS would be preferred.

More commonly, AMS provided concentration data and the NCD machine provided isotope ratios. In these cases the noble gas concentrations were entered as key 3 = AMSBIG, which would very likely be the only choice for noble gas data. Results based on isotope ratios combined with AMS concentrations (1..g. XsXe136, Kr85, xsNe22, etc.) were entered in table 1 as measurement key 5 = MASS SPEC. From there, they were carried through the radionhemical results calculations. 
VII. Detailed Description of the Individual Tables

\section{Preshot Data Summary Tables}

Immediately following the listing of the imput deck are two tables summarizing the preshot information. The first of these is a summary of tracer and detector loads for the event. The second is a listing of mass spectrametric analyses results for any samples obtained preshot. These tables are printed only once for each input deck (as opposed to the postshot data tables which are modular in nature and are repeated for each tracer species present in the input).

Each tracer and detector species is summarized seperately. The first line gives the species, the amount loaded, and its assigned uncertainty. The second line serves as a column heading for the rest of the table, and is comprised of the component isotopes of the species being summarized. The third line gives the mole fractions of each isotope in the material loaded. The final two lines give the totals present in liters (STP) and in atoms.

DEIPHI could be instructed to select a particular mass spectrometric analysis type to use for the loaded tracers or detectors. These are indicated at the end of the table. If no specification is made, DELPHI defaults to the AMS analysis of the "BIG" cylinder (and prints this fact).

The preshot analysis table header gives the sample number (usually of the form $9 x$ ), the sampling time (negative days, or days before the event zero time), and the sample source key. The main body of the table is a sinple listing of all available data for the preshot samples. Mass spectrometric results are listed as mole fractions accompanied by the percent standard deviation. Radionuclide concentrations are generally listed as atoms per liter(STP), but could also be OY TH F/L or DPM/L if the printout is an old one. Indicated errors are one standard deviation of a measurement based on replicate determinations, and expressed as percent.

\section{TABLE 1. RADIOCHEMICAL RESULTS}

The radiochemical results table accumulates measured data for all radicactive species and stable isotope concentrations usually expressed in units of atoms per liter (STP). Early (pre 1972) versions of DEIPHI used oy thermal fissions for the fission product gases. Non-fission, radioactive species in the early DELPHI's were expressed as disintegrations/minute/liter (STP) (dpom/l).

* See footnote, page 5 
The table generally contains results for all fission and activation product species as well as detector product concentrations, if detectors were loaded. It can contain tracer concentrations if the

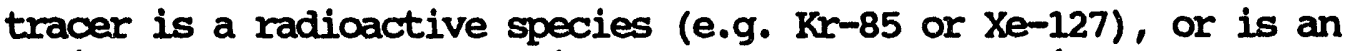
enriched stable noble gas isotope. Results from five measurement techniques can be entered. These are identified by the measurement key.

In Table 1. the onder and significance of the output entries is:

Line 1. DATE OF CALOULATION. This is the time and date of the computation. Note that the data can precede the DELPHI computation date by a significant time span. Dates of pre-DEIPHI data processing appear in the imput deck as comment cards for recent events. To be sure that the DEIPHII data tables contain the most recent (presumably best) data one must consult the event notebook.

Line 3. Radionuclide Measurement Key. The line lists the memonic keys for the five measurement techniques used to determine radionuclide concentrations. (See definitions on page 6.) The key numbers applicable to each data entry row are printed after the muclide designation in the radiomuclide data tables.

Line 4. SAMPLE NUMBER. Column headings are the designated sample numbers. These are generally assigned in order of receipt of the sample.

Line 5. TIME (+DAY). Sampling time is entered for each sample in days following event zero time. Sampling times are given to the nearest 0.001 day $(1.4 \mathrm{~min}$.$) .$

Iine 6. SOURCE KEY. Source of the sample is entered as a key mumber. These entries are of the form X.YYY where $X$ is a system identifier and $\mathrm{YYY}$ is the conduit length in tens of feet. $\mathrm{X}=1$ is used for the prompt sample hose. $X=2$ is used for post-shot re-entry drillback sampling. Other values of $X$ are assigned as needed. These definitions are entered in the sample log book.

Line $8 \mathrm{ff}$ DATA ENIRIES. Concentration data are listed by muclide for each measurement key and for up to 10 samples. Data are atoms per liter (STP) for output printed after 1972. Beneath each concentration value is its percent uncertainty (one standard deviation of the mean of replicate determinations). 


\section{Table 2. Total Atoms}

The total atoms table has much the same format as the preceding table of radionuclide concentrations. The first line gives the shot. Series, the Nuclear chemistry ID number, and the zero time for the event (PDT). Line 2 identifies the table and specifies the tracer species which will be used for calculations throughout the module. The tracer load, the units of its expression, and its standard error (q) are also given. For stable gas tracers, the units are usually liters (STP). Radioactive gas tracers are generally given in units of total atoms, except for $\mathrm{Kr}-85$ which was entered as oY Thermal Fissions in early versions of DELPHT. (see footnote, page 5) The next three lines reiterate the sample number, the sampling time, and the source key as described for Table 1 .

The next two printed lines give the calculated reciprocal device fraction (1/F) and its percent standard error. (1/F) is the total number of liters of gas required to dilute the loaded tracer to the measured concentration in the sample (assuming uniform mixing). The expected value for good samples is $1.5 \mathrm{E}+07$ liters per Kt total device yield. Larger numbers indicate poorer samples, smaller numbers may indicate poor mixing. In general the calculation of reciprocal device fraction is given by equation 1.

$$
\text { 1) } 1 / F=10 a d /((\text { tracer }) s-(\operatorname{Ar}) s \times(\operatorname{tracer} / \mathrm{Ar}) \mathrm{a})
$$

where load is the total amount of the tracer species known to be present, expressed in liters (STP), atoms, or OY TH F, as appropriate. The "loaded" amount includes contributions from all sources (i.e. loaded material, impurities in other loaded tracers, fission and thermonuclear debris, etc.) The term (tracer)s indicates the concentration of the tracer gas in the sample as received, (Ar)s is the concentration of argon in the sample, and (tracer/Ar)a is the normal air ratio of the tracer species to argon. concentration units for stable gases are mole fractions, while radioactive species can be atoms, dpm, or OY TH F per liter (STP).

Displayed beneath the $(1 / F)$ percent uncertainty line is the bomb fraction per liter (STP) of sample (BF/LSTP). This was included for the benefit of radiochemical diagnosticians accustomed to working with device fractions, and was never actually used by DETPHI. It is, of course, just the "F" in the reciprocal device fraction (1/F).

DETPHI applied an air correction to the tracer concentration if the tracer species was also a component of normal air (e.g. $\mathrm{Kr}$ and $\mathrm{Xe}$ ). Argon was the air indicator. Lines 9 and 10 of the total atoms table give the variances of the tracer and argon measurements used to calculate the error in the reciprocal device fraction. If isotopically enriched tracer gases were used, the air correction was applied externally, and only the excess was entered for use in the code (e.g. xsNe22). He-3 was a common tracer gas for $\mathrm{He}-4$, and required no correction. 
Rn-222 was used as a tracer on same early (pre 1965) events. The intersticial gas in soil was estimated to contain $5 \times 10^{6}$ atoms of Rn-222 per liter at equilibrium. About $1 \times 10^{7}$ liters of rock per $\mathrm{kt}$ total yield release gas to the cavity at early times. If the rock is $20 \%$ air filled voids, then the background $\mathrm{Rn}-222$ would be $1 \times 10^{13}$ atoms per $\mathrm{Kt}$ total device yield. The amount loaded was typically several onders of magnitude larger (we had a 18.5 curie radium source, and could load as much as $1 \times 10^{17}$ atoms of $\mathrm{Rn}-222$ at shot time). Hence, the background $\mathrm{Rn}-222$ was generally ignored. Nevertheless, we attempted to correlate Rn-222 with other soil gases (i.e. He-4 and Ar-38) to get a measure of the correction and allow smaller loads. These attempts were unsuccessful. We ceased the use of $\mathrm{Rn}-222$ as a tracer material in 1966.

The last line of the table heading lists ratios of the fraction of the total tracer species which is in excess of that contributed by air to the total of the tracer species in the sample (TRCR/TOTAL). The entries are, of course, only meaningful for $\mathrm{kr}$ or $\mathrm{Xe}$ tracers. In terms defined for equation 1, the values of TRCR/TOTAL are:

2)

$$
\text { TRCR/TOTAL }=\frac{(\text { tracer }) s-(\text { Ar }) s \times(\text { tracer } / A r) a}{(\text { tracer }) s}
$$

The TRCR/TOTAL in well mixed cavity gas was generally 0.9 or greater by design. Lower values were frequently seen in sampled gas, and were attributed to air dilution during transport of the cavity gas to the sampling system inlet. Values less than 0.5 would cause a sample to be suspect. Very low values (i.e. 0.1) would cause the sample to be rejected, unless that was the best we could obtain.

The body of the total atoms table gives the totals of the various species and their percent uncertainty on a sample by sample basis.

3) total atoms $=($ atoms $/$ liter $) s \times(1 / F)$ liters

Printed before the errors of the measurements (on the same line) is a key letter indicating the status of the measurements. A "W" stood for "First Wild Guess", and indicated that the counting was incomplete. A "P" stood for "Preliminary" and indicated that counting was well along and that some data massaging had occurred. The "F" stood for "Final", and indicated that counting was complete and all corrections had been made. This process worked well for measurements made by beta decay curve resolution (Key $1=$ BETA and Key $2=$ LOBACA), but was less automatic (and therefore frequently ignored) for other measurement techniques. The rightmost column is the average for each constituent and the percent standard deviation of a measurement associated with the average. 
A word of CAUTION: During the GROMMEI series in 1972, the Gas Diagnostics group adopted the vse of atoms/liter or atoms as the units for expressing all radioactive species. Prior to that time fission products (including $\mathrm{Kr}-85$ tracer) were expressed as oralloy Thermal Fissions, and non-fission radioactive species were entered as disintegrations per minute. During 1972 a major effort was made to convert previous data to an atom scale for insertion into the PROPHEN database. Thus, two databases existed for the gas data. DEHPHIs run prior to 1972 (if any still exist) would have used the old decks, and should be self-consistent (i.e. OK). However, DELPHI was rerun in the late 1980's for archival purposes (the 7600's were being replaced and the archived data storage facilities were being reconfigured). In, at least, some instances the converted decks were used for this rerun. However the tracer data was not converted. In circumstances where $\mathrm{Kr}-85$ tracer was expressed as $\mathrm{OY} \mathrm{TH} F$ and the $\mathrm{Kr}-85$ measurements were atoms/liter, the derived totals (and fission yields) would be too large by a factor of $3.08 \times 10^{3}$ (=0yThF/Kr-85 atom). Similarly, totals derived from $\mathrm{Rn}-222$ expressed as dpm from measurements expressed as atoms/1 would be too lange by a factor of $7.95 \times 10^{3} \quad(=1 / 1$ ambda for $\mathrm{Rn}-222)$. The best way to tell if one of these "gotcha" printouts is upon you is to look at the fission yield tables (tables 4 and 5). If you are expecting kilotons and the printout gives megatons, then one of the above correction factors is needed.

\section{Table 3. Atoms per Fission}

This table was of use during the development of Gas Diagnostics as a means of determining the yield of gaseous fission products. It is simply a tabulation of the entries in the total atoms table (table 2.) divided by the number of total device fissions. This total fissions number was manually input to DELPHI, and came (usually) from device performance predictions or from core sample analysis. The table was generated only when a total fissions input card was present in the input deck. Once adequate measurements were obtained, and following introduction of more complex device designs, output of this table was uncommon. Laboratory experimental measurements generally supplied most of the subsequent requirements for yield data.

\section{Table 4. Fission Split}

The fission split assumed for the test device is output under the table heading. The split was an imput quantity, often coming from the device designer, but occasionally was determined (outside of DEIPHI) from a least squares fit $t$, the experimental measurements for several fission product gases. Note that the split is given as the actual fraction of each type of fission (summing to unity for the total device), not by fissile material and fraction of high energy fissions in each material as was the customary practice in solid core diagnostics. 
The two bin energy model for neutron induced fission was used by DEIPFI. The Bins were: 1) fission spectrum neutron induced fission, using yields determined by irradiation of fission targets in the fission plate facility at the Livermore Pool Type Reactor (IPIR) or fram actual fission devices, and 2) high energy neutron induced fission, using yields determined by irradiation of fission targets at the Rotating ranget Neutron Source (RINS) or the Isolated core Transformer irradiation facility (ICT) .

Up to six types of fission could be used by DEIPII. These were U-235, U-238 and Pu-239 targets with either fission spectrum or high energy neutrons. Table entries under these headings are " $Q$ " values $(Q=$ atoms per fission of a particular type divided by atoms per fission of U-235 induced by thermal neutrons). Non-measured "Q"-values are entered as unity.

The fission product gases are listed in the leftmost column. A designation such as $\mathrm{Kr}-85$ or Xe-135 denotes chain yield. The "Q"-values in those rows involve ratios of apparent zero time atoms for complete chain decay (i.e. late time measurements extrapolated to zero time). Entries with a "D" appended, such as Xe-135D, are ratios of the independent atom yield of the species to the apparent chain yield for U-235 thermal fission (again expressed at time zero). The independent yields were determined by dissolution of the targets as soon as possible after irradiation, prompt flushing of the fission gases from the dissolution flask, and several additional, appropriately timed, flushes of the flask to measure the fission gas growth rate. These data were fit to the Bateman equations (by a code called RHOZEE) to obtain the independent yields entered in the table.

Column 7 summarizes the "DEVICE Q" values. These are the sum of the individual " $Q$ "-values for each fission type weighted by the assumed fraction of each type of fission (the split values). Colum 8 simply lists the apparent absolute yields (atom yields for a late time measurement extrapolated to zero time) for each species from U-235 thermal fission (OY TH AT/F). The rightmost column is the product of the "DEVICE Q" and the "OY TH AT/F" values, and is the mumber of specie atoms (chain or independent) expected per device fission for the mix of fission types given by the split ("DEV AT/F").

\section{Table 5. Fission Yield (chain)}

Irmediately following the Fission Split table is the Device Fission Yield table. Its heading gives the number of fissions per kiloton of device yield calculated using the fraction of each type of fission given in the Fission Split table. Also entered in the heading is the tracer load, and the sample number, time, and source key (as before). The reciprocal device fractions $(1 / F)$ and their uncertainties $(q)$ are repeated at the top of the table. 
The table entries are total fission yields (Kt) for the device determined for each fission product species and each measurement type on a sample by sanple basis. Each row is averaged, and the percent standard deviation of a measurement calculated. These results are summarized in the rightmost column. In this table only the DEV AT/F values for chain yield are used. The calculation of total device fission yield is straightforward:

3) total device fission yield (Kt) = (total atoms of fission product) (DEV AT/F) $x$ (fissions/Kt)

In equation 3) the total atoms of fission product is obtained from table 2, the device atams per fission from table 3, and the fissions per kiloton from the header of table 4.

Because table 4 involves only DEV AT/F values for chain yields, it is generally useful only for species with short lived precursors $(\mathrm{Kr}-87, \mathrm{Kr}-88, \mathrm{Kr}-85 \mathrm{~m}, \mathrm{Kr}-85, \mathrm{Xe}-136)$. Uniform mixing of the rare gas fission products with the device fraction tracer is an underlying assumption of any calculation that derives totals. Mixing is not likely after chimney subsidence, and often samples taken post subsidence, even at very late times relative to precursor decay, did not produce meaningful results. Most xenon fission product measurements were, therefore, simply ignored unless samples were obtained early enough that they could be considered to be independent yield only. (see table 6.)

Another caution regarding late time sampling involves differential mobility of the tracer and the desired measurement species. Differential mobility includes both gaseous diffusion rate differences and rhromatographic separation effects (solubility and adsorption). The importance of isotopic tracers was recognized in the early 1980's to eliminate these concerns. Prior to that time, it was the general belief that once gases mixed they would stay mixed. Under this premise tracers were not necessarily isotopic counterparts of the species to be traced. For example, it was customary to use krypton to trace xenon fission products, and to use argon to perform the air correction. Even when xenon was loaded as a sevond tracer it was often discounted because of its poorer analytical accuracy compared with krypton. I would now recormend that such data be considered suspect until proven otherwise. The best clue to the presence (or absence) of differential mobility effects is in the gas to tracer ratio tables near the end of the LEIPHI printout. Another indication is the agreement between fission yields based on krypton and those based on xenon. If disagreement exists, the preferred values would be those obtained from tracer/species pairs of similar mobility. 
Table 6. Fission Yield (independent)

Inmediately following the fission yield table based on chain yields of the fission indicators is the table entitled "INIERPRETED AS DIRECT FISSION YIEID". This table is identical in format and ocmputational details to the preceding table except that it uses only the "DEV AT/F" values for independent (direct) fission yield. Because of this, the cable is only of use for samples taken early as compared with precursor decay times.

Typically Xe-135 in samples taken within a few hours of zero time can be considered independent yield (the I-135 precursor has a $6.6 \mathrm{hr}$. halflife, and the Xe-135 yield is about half the chain). Xe-133m, with a 21 hour precursor halflife can be considered to be independent yield for several hours. Xe-133 is more complicated. Independent yield favors the Xe-133m, while precursor decay favors the ground state. Thus, ingrowth from I-133 "perturbs" the ground state more rapidly than the metastable state. The Xe-133m also decays to the groundstate with a 2.2 day halflife.

Correction for this ingrowth is applied to the data by the BRUNHIIDE code for ganma spectrometric determinations prior to imput to DELPHI (if both Xe-133m and Xe-133 are seen in the spectrum). Often the correction is large relative to the residual, resulting in amplification of the uncertainties. The best indicator of precursor ingrowth is the $\mathrm{m} / \mathrm{g}$ ratio, which will be about 3 for independent yields and can drop to 0.05 for chain yields (exact values can be obtained from the DEV AT/F tables for the particular split assumed for the device). For the 133 chain the preferred indicator is Xe-133m in mosic. cases.

Other fission products listed include Xe-131m, Xe-129m, and $\mathrm{Xe}-127$. Xe-131m is "shielded" by 8 day I-131, and is likely to be independent yield for many hours. It was a valuable split indicator, since its production in high energy neutron induced fission is more than 200 times its production by fission spectrum neutron induced fission. Xe-129m and Xe-127 are both shielded from ingrowth, and are produced in fission only as independent yield species. They were also useful as split indicators, but their absolute fission yields were not well known. Note: both Xe-129m and Xe-127 could also be present in the debris due to the loading of Xe-124 as an $(n, 2 n)$ detector. (The Xe-124 used was only $40 \% \mathrm{Xe}-124$. It also contained $8 \% \mathrm{Xe}-126,12 \% \mathrm{Xe}-128$ and $35 \%$ Xe-129 as well as lesser amounts of the heavier xenon isotopes.) check the detector tables for confirmation. 


\section{Table 7. Summary of Gas Diagnostics Detector Data}

During the early $1980^{\prime} \mathrm{s}$, we experimented with the use of $\mathrm{Kr}-78$ and $\mathrm{Xe}-124$ as gaseous $(n, 2 n)$ detectors. This effort gave way in the later part of the 1980's to the development of Br-79 and I-127 as charged particle detectors $(p, n$ and $d, 2 n)$. Table 7. summarizes the results for those events utilizing these species as detectors (i.e. the table is present only in those printouts where detector loadings are specified in the imput deck). Each detector is summarized separately, but sequential tables in each module utilize the same tracer gas. Hence, as discussed above, caution should be exercised to avoid problems caused by differential separation effects. In general, $\mathrm{Kr}-78$ and $\mathrm{Br}-79$ activation products should be quantitated using $\mathrm{Kr}$ tracer and $\mathrm{Xe}-124$ and I-127 activation products should use Xe tracer (both $\mathrm{Kr}$ and Xe tracers were present throughout the series of detector development experiments). The $\mathrm{Kr}$ and $\mathrm{Br}$ products vs Xe tracer, and $\mathrm{Xe}$ and I products vs $\mathrm{kr}$ tracer tables were output proforma, and should be ignored.

Input data for the detector load is summarized in the first several lines. The principal detector isotope is identified, the load (ISTP for gases or grams (GM) for solids) and its percent uncertainty (PCT ERROR) is listed, the fraction of the load actually introduced to the active region of the device is given (FRACTION FIILED), the molecular weight of the loaded material (MOL WT) is listed, and the location (stage) of the load is identified. The isotopic composition of the detector is then normalized to sum to unity excluding any impurities, and a correction factor to the total load is calculated to acoount for the impurities (entries for the sum of all impurities are arbitrarily identified with a ZZAAA of 99000). Finally, the isotopic composition of the detector species is tabulated in units of mole fractions and the total atoms of the detector species present in the active region of the device at zero time is calculated.

The remainder of the table consists of a sample by sample listing of the fractional conversion results for the tracers. This is simply as shown in equation 4):

4) Fractional conversion $=$ total atoms of product total atoms of target in the active ragion

The values for total atoms of product are calculated in a manner analogous to that described for table 2. No correction for other possible sources of the product species is applied (i.e. fission). In general, the loads were selected such that the desired products were enough in excess of the extraneous sources that ignoring this correction was justified. The total atoms of target in the active region was calculated from the input data, and is listed at the top of this table. The summary of tracer and detector loads table, which appears immediately following the input deck listing at the start of the DEIPHI printout, is a seperate (and equivalent) calculation. 
When available, the printout lists conversion fractions for ( $n$, gamma), $(n, 2 n)$, double $(n, 2 n)$, and $(p, n)$ or $(d, 2 n)$ reaction products relative to the principal detector species. In general, measurement of the ( $n$, ganma), double $(n, 2 n)$, and charged particle products was accomplished by gamma spectrometry on separated fractions of the corresponding noble gas. The single $(n, 2 n)$ products were too short lived to measure in separated fractions, and were typically too low activity to measure in unseparated (gross) sample gas. A number of experiments were undertaken to try to abtain measurement of these species through their daughter products.

For the $(n, 2 n)$ products the measurement technique evolved into the use of a silver filtered, field filled, high pressure counting cell for each sample. These cells were filled by expansion fram the sample bottle when we returned to the sampling trailer for recovery of the samples prior to their removal from the sampling skid. The idea was to separate halogens from noble gases at fill time, allow the halogens daughters to grow in and (hopefully) plate out on the cell walls, pump off the mixed fission products in the gas, and measure the halogens as representative of the $\mathrm{Kr}$ or $\mathrm{Xe}$ parent present initially.

When measurement was made of a halogen daughter in a full (as received) field cell the isotopic mass in the identification key (ZZAAA) was incremented by 100 (e.g. 36176 indicated $\mathrm{Kr}-76$ fram double $(n, 2 n)$ reactions on $\mathrm{Kr}-78$ measured as $\mathrm{Br}-76$ in a full field cell by gamma spectrametry). When the cell was pumped out, and the measurement based on a halogen daughter plated out inside the cell, the isotopic mass was incremented by 200 (e.g. 36277 was $\mathrm{Kr}-77$ determined fran Br-77 remaining in the cell after pump-out). Note: Measurements based on the halogen daughters were processed by a code named "PDQ" prior to imput to DEIPHI to obtain the equivalent zero time concentration of the noble gas parent.

Measurements based on halogen daughters were subject to many uncertainties. We were never sure that the counting cells were initially free of halogens at fill time (experiments to test the effectiveness of the silver pre-filter were never completed, and the RINS source of the $\mathrm{Kr}-77$ activity was decommissioned). We were also never sure that halogens grown into the cell were quantitatively retained during the pump-out process. Retention was good from an atmosphere of krypton. Early experiments, using separated $\mathrm{Kr}$ fractions in aluminum cells, gave good agreement between "before" and "after" measurements. However, cavity gas in stainless steel cells did not. Perhaps the reactivity of the cavity gas led to the formation of volatile $\mathrm{Br}$ and I compound(s) allowing their escape during pumpout. We had intended to introduce charcoal filtration (both at fill and at pumpout) to evaluate and correct for these uncertainties. The opportunity did not present itself. The program was discontinued, along with the prompt gas sampling effort, in 1988. Bottom line: use measurements reported for $\mathrm{Kr}-77$ and Xe-123 with caution. Other products should be OK. 


\section{Table 8. Mass Spectrometry Results}

This table lists all the concentration results from mass spectrometric analysis of the samples. The header lists the analysis source keys for the two sizes of sample cylinders and three analytical techniques. It also gives the usual listings of the sample number, sampling time and sample source key. This standard header is repeated at the top of each of the data tables summarizing mass spectrometric data.

Typically, during prompt sampling operations, both a 15000 and a $250 \mathrm{c}$ sample cylinder were present at each sample port. These were referred to in the printout as "BIG" and "SMALL", respectively. The $25 \mathrm{cc}$ cylinder was sent to LINL for determination of shortlived radionuclides whenever the $1500 \mathrm{c}$ cylinders were too radioactive to ship. The $1500 \mathrm{c}$ cylinders were shipped later (after a sufficient decay period) and were used for determination of the longer lived radionuclides and noble gases.

The $250 \mathrm{c}$ cylinders were separated from the $1500 \mathrm{c}$ cylinders by about 4 feet of 1/4" stainless steel tubing on the sampling skid. Although both cylinders were open during pumping of the sample, and filled at nominally the same time, we did not assume them to be equivalent. often, and particularly when gas composition was changing during sampling, the gas composition was measurably different in the two cylinders. Analysis of each was required to normalize measurements to a common base.

Samples taken by other than prompt sampling techniques (late time, grab, drill hole tubing, etc.) were always identified as "BIG". These were of at least 10 liters (STP) in volume, and could be collected in a variety of cylinder sizes and configurations. No "SMALL" cylinders were obtained in these samplings.

The principal analytical technique for determination of gross chemical composition of the samples was referred to as Analytical Mass Spectrometry (AMS), and was developed and operated by the chemistry and Materials Science Department. Gas at known pressure was admitted to the ion source and the signal/unit pressure was compared to that for known standards to determine the partial pressure of each component of the sample. Concentrations were obtained by normalizing the sum of the constituent pressures to unity. Identification of constituents in gross samples was based on a routine (the Tunnicliff code) that matched cracking patterns of individual components to the mass spectra of the sample. The technique provided gross composition measurements for both "BIG" and "SIMAIL" samples throughout the history of Gas Diagnostics.

AMS was also the principal measurement technique for the noble gases in the early years, and continued to be used routinely until the mid 1980s when separated isotopic tracers became available. For noble gas analysis by AMS, approximately one liter aliquants were gettered 
over molten calcium, and the noble gas residual was analyzed to obtain ratios of the various rare gases to Argon. The argon concentration determined in the gross analyses was then used to obtain the rare gas concentrations in the original sample. This technique was limited to "BIG" sample cylinders because of the volume of gas required.

In the late 1970s, the nuclear Chemistry Division built and began operating a high-sensitivity, high-precision stable-isotope gas mass spectrameter system for determination of the noble gas concentrations. This technique utilized small (fractions of a $\infty$ ) aliquots, performed on-line gas separation, and measured isotope ratios of the noble gases. Combining a gross analysis with one containing a known amount of an isotope of each noble gas (spike) allowed determination of the noble gas concentrations (referred to as Isotope Dilution Mass Spectrometry, or IDMS). The system could provide soble gas concentrations and isotope ratios for both the "BIG" and "SIMLL" sample cylinders.

The results in table 8 , and all other mass spectrametric analysis summary tables, are given as mole fractions. Most species are identified by their chemical symbol or formula. "GUNK" is a pseudonym for anything else the mass spec identification routine thought was present. "GUNK" is typically heavy hydrocarbons $\left(C_{4}+\right)$. Water vapor is igno: ed by the AMS data reduction routine, and is not reported. Some isotopic ratios (e.g. D2/H2) are listed as well. Beneath each entry is an estimated uncertainty $(+/-\xi)$, based on the analytical agrement between replicates. The uncertainty was not allowed to be less than $+/-0.5 \%$. Values entered with smaller uncertainties were arbitrarily revised to this minimm. If no uncertainty estimate was input with the data the $+/-0.5 \%$ value was assigned, and the entry was flagged with a question mark (?). Also, a category (W, P or F) could be included to indicate the status of the analysis. A "W" usually meant a first result, often from the small cylinder. A "p" was assigned to early results prior to validation. The "F" was used to indicate that validated replicate results were entered.

\section{Table 9. Selected Analytical Results}

Table 9 is identical to table 8 in form and content. The only difference is that a particular analytical source and cylinder size has been selected for the gross and rare gas results to be used henceforth. The sources selected are indicated in the second line of the header.

\section{Table 10. Normalized Mass Spectrometric Data}

Table 10 is identical to table 9 in form. The uncertainties in the measurements are not included, and the concentrations of the components of each sample (except the rare gases and isotope ratios) have been normalized to sum to unity. 


\section{Table 11. Totals of Chemical Constituents}

Totals of each camponent of the samples are tabulated in table 11. These values are simply the mole fractions listed in table 10 times the reciprocal device fractions (1/F) for each sample. The $1 / F$ values are identical to those described in the discussion for table 2. The tracer concentrations for species which are components of normal air have been adjusted to correct for air dilution based on argon in the sample (see Eq. 2.) Values used for the quantity $1 / F$ are given beneath the header of table 11 for reference. Also included, beneath the $1 / F$ entries, is the percent uncertainty assigned to the $1 / F$ values.

The components of table 11. are not adjusted for air dilution. (This is the meaning of the entry on the title line of the table which states "NO AIR REMOVED".) Therefore, the totals given in the table can be thought of as representing a uniform mixture of air and cavity gas to give the concentrations of all components as seen in the sampled gas. For components of both normal air and cavity gas these entries can be misleading. Typically, some localized incorporation of air from the region near the sampling hose inlet was experienced cturing sampling. This means that the air component totals will be severely overestimated as a consequence of the uniform mixture assumption. For components of cavity gas alone, the totals given in table 11 are acceptable at face value.

\section{Table 12. Removing Components of Air Based on Oxygen}

This is the first of two attempts by DEHPHI to calculate the composition of cavity gas from the sample measurements. Here the oxygen content of the sample is used as the air indicator, and the concentrations of all components of normal air are subtracted from the measurements. The results are renormalized to sum to unity. For reference, the definition of normal air used by DEIPHI is printed prior the the start of the table.

Beneath the title, the selected sample source and analytical technique are indicated and the definition of the code numbers is repeated. DEIPHI raises a warning flag if the sample is more than 95\% air (SAMPLE n AT IEAST 0.95 AIR, WEIGH RESUIIS IIGHILY). At $99 \%$ air DELPHI refuses to calculate the results. These warnings appear just prior to the standard header information for the table.

The first line of the table is the fraction of the original sample which is air (based here on oxygen). The calculation of the fraction that is air is simply:

$$
f(\text { air })=\left[\mathrm{O}_{2}\right] \mathrm{s} /\left[\mathrm{O}_{2}\right] \mathrm{a}
$$

where $f(a i r)$ is the mole fraction of air in the sample, $\left[\mathrm{O}_{2}\right]$ s is the oxygen content of the sample, and $\left[\mathrm{O}_{2}\right] \mathrm{a}$ is the oxygen content of normal air $(20.946 \%)$. 
Each component in the aic free resicual is listed under the heading "Cavity Gases". These are the concentration data from table 10, corrected for air using the $f(a i r)$ values obtained from equation 5 . The residuals are renormalized to sum to unity. The calculation is:

$$
[X] \text { noair }=\frac{[X] s-\left(\left[O_{2}\right] s \times\left[X / O_{2}\right] a\right)}{(1)}
$$

where $[X]$ noair is the renormalized air iree concentration of component $X,[X] s$ and $\left[O_{2}\right]$ s are the normalized concentration of component $X$ and oxygen in the as received sample (from table 10.), $\left[\mathrm{x} / \mathrm{O}_{2}\right] \mathrm{a}$ is the ratio of component $x$ to oxygen in normal air, and $f(a i r)$ is the fraction of the original sample that is air based on oxygen (equation 5).

All components of the sample are corrected in the manner of equation 6 , including the rare gases and any isutope ratios (e.g. D2/H2) that are listed. (The latter is a "feature" of DEIFHI, since the $\mathrm{D} / \mathrm{H}$ ratio is essentially independent of air dilution. The renormalized ratio has no real meaning, and should be ignored. The step was neasssary in order to retain the correct total $\mathrm{D} 2 / \mathrm{H} 2$ value in subsequent tables.)

\section{Table 13. Totals After 02 Air Removed}

Following the standard heading for mass spectrametric data tables, DELFII prints a line labeled "Liters STP/NO AIR". These values are the equivalent of the 1/F values used previously, but pertain to the cavity gas resicual after removal of oxygen based air, as given in table 12. The gas volume is abtained from:

7) Liters STP $=\frac{\text { total tracer loaded }}{\text { NO AIR }}$

where the air corrected consentrations of tracer and argon are those listed in table 12, and [ $\mathrm{Tr} / \mathrm{A} \mathrm{Y}$ ] air is the atmospheric ratio of the tracer to argon. Beneath these entries are listed the percent uncertainties in the volumes.

The next line gives "TOTAI, AIR". This is most easily visualized as being the difference between the total gas volume deduced prior to air subtraction and that derived after the air correction. It represents the total volume of normal air (i.e. having the textbook ratios of the air gases) that would need to be mixed uniformly with the residual (cavity gas) to give the observed sample camposition. However, local mixing with a much smaller amount of air could produce the same result. 
Entries in the Totals after $\mathrm{O}_{2}$ air removed table under the subheading "CAVITY GAS" are simply the product of the total gas volume after air removal ("LTIERS STP/NO AIR") and the composition data given in table 12. For non-air gases, these values are the same as those given in table 10. Isotope ratios are also returned to their initial values, as expected. For air gases, $\mathrm{O}_{2}$ is small (that it is nonzero is likely due to round-off problems in the differencing of mubers of similar value), $\mathrm{N}_{2}$ and Ar usually remain as 2 significant portion of the corrected sample composition.

In some circumstances (e.g. Gas stimulation experiments) an air correction based on $\mathrm{O}_{2}$ may be a realistic endeavor. In most nuclear cavities, however, this correction is generally a rather poor approximation of reality. There are several reasons for this...the most important being that $\mathrm{O}_{2}$ is reactive. It can, and does, react with various components of cavity gas (principally $\mathrm{H}_{2}$ ) and become separated from the gas. $\mathrm{O}_{2}$ is a major component of the surrounding rock matrix and can be both produced and consumed during and after the detonation. Most events characteristically show oxygen depletion in the cavity gas relative to either nitrogen or argon. Events detonated in Rhyolite characteristically show oxygen enrichment. There are too many "sources" and too many "sinks" for oxygen to enable its reliable use as an air indicator. DEIPHI uses a two part air correction to get around these problems. The second step, and a more realistic approximation, uses argon as the basis for the final air correction. The results of these manipulations are summarized in the following two sections.

\section{Table 14 - Removing Additional Oxygen Free Air Based on Argon}

Rarely does the air correction based on oxygen account for all of the air components seen in the sample gas. In order to more fully correct cavity gas components for air dilution it was customary to repeat the air correction computations using argon as the air indicator and a hypothetical entity called "oxygen free air" as the diluent.

On the line following the normal header information, table 14 lists the amount of oxygen free air based on argon that was removed from each of the samples. The calculation is analogous to that of equation 5.

$$
\text { 8. AIR OUT }=\left([\mathrm{Ar}] \text { no } \mathrm{O}_{2} \text { air }\right) /\left([\mathrm{Ar}] \mathrm{O}_{2} \text { free air }\right)
$$

where ( $[\mathrm{Ar}]$ no $\mathrm{O}_{2}$ air) is the concentration of Ar after the oxygen based air correction and renormalization to unit sum (table 12) and ( $[\mathrm{Ar}] \mathrm{O}_{2}$ free air) is the Ar concentration in oxygen free air $(1.1817 \%)$. 
The remainder of table 14 is a tabulation of the cavity gas concentrations after removal of the argon based oxygen free air. values are normalized to sum to unity. The calculation is analogous to equation 6 .

$$
\text { 9. }[\mathrm{X}] \text { no Ar air }=[\mathrm{X}] \text { no } \mathrm{O}_{2} \frac{\text { air } \left.-\left([\mathrm{Ar}] \text { no } \mathrm{O}_{2} \text { air }\right) \times[\mathrm{X} / \mathrm{Ar}] \mathrm{a}\right)}{(1-\operatorname{AIR} \text { OUT })}
$$

Where ( $[X]$ no Ar air) is the renormalized concentration of component $X$ after subtraction of oxygen free air based on $\mathrm{Ar},\left([\mathrm{X}] \mathrm{no} \mathrm{O}_{2}\right.$ air) and ([Ar]no $\mathrm{O}_{2}$ air) are the concentration of component $X$ and $A r$ in the oxygen air corrected sample. and [X/Ar]a is the ratio of component $X$ to Ar in normal air. AIR OUT is the mole fraction of the oxygen free air that was removed (from equation 8). As before, the correction is applied to all sample components, including oxygen, the rare gases and any isotope ratios. In many cases this calculation will produce negative results (often for $\mathrm{O}_{2}$, sometimes for $\mathrm{N}_{2}$, and occasionally for some of the rare gases). These negative concentrations are ignored in the summations.

\section{Table 15 - Totals ... Ar Air Removed}

The totals table is analogous to table 13, except it excludes air components in the normal atmospheric relation to argon contained in the sample. The totals are calculated fram the concentrations given in table 14 following the oxygen free air subtraction based on Ar from the samples. The normal header information precedes the table. The total cavity gas volume, entered as the quantity "LITIERS STP (NO AIR)", is obtained from the tracer concentration in table 13, and is identical in form to equation 8:

$$
\text { 10. LITERS STP (NO ATR) }=\frac{\text { Total tracer loaded }}{\text { [tracer] no Ar air }}
$$

Beneath the values for the total cavity gas volume (no Ar air) the uncertainties assigned to the tracer measurements are repeated (from table 2). The third data line is the total amount of oxygen free air removed in the last correction. The "TOTAL AIR" entry is simply the LITERS STP (NO AIR) obtained fram the $\mathrm{O}_{2}$ air correction mimus the equivalent quantity obtained from the oxygen free air correction based on Ar.

The remaining entries in table 15 are the totals of the various components remaining after the final air correction.

11. Total $\mathrm{X}=$ LTTERS STP (NO AIR) $\mathrm{x}[\mathrm{X}]$ no Ar air Negative values are permitted, but are not included in the summation. 
The concentrations given in table 14, and the corresponding total gas volumes given in table 15, describe a "Cavity Gas" that is devoid of argon, oxygen, and other air components in proportion to the argon that was subtracted. Excesses of air gases (i.e. $N_{2}$ from the high explosive, he from outgasing of the rock, $\mathrm{CO}_{2}$ from decomposition of the rock, etc.) stand out as positive values, and can be used to help to delineate such interesting phenomena as the amount of rock releasing gas, the cavity gas chemistry, and extraneous (usually I-Div.) sources of gases sometimes loaded to provide a dry atmosphere for electronic components. The user is cautioned, however, that true cavity gas must usually contain some air (typically the air filled porosity in 3 to 5 melt radii). Also, since $\mathrm{O}_{2}$ free air cannot truly exist, the fact of ignoring any $\mathrm{O}_{2}$ deficit can underestimate the relative importance of species such as $\mathrm{H}_{2}$ and $\mathrm{CO}$ that were likely depleted due to reaction with the missing $\mathrm{O}_{2}$. More recent air correction algorithms use Ar as the air indicator and treat negative concentrations (i.e. "missing $\mathrm{O}_{2}$ ") by adding twice the missing $\mathrm{O}_{2}$ to $\mathrm{H}_{2}$ to obtain a better approximation of cavity gas composition. This assumes that the missing $\mathrm{O}_{2}$ was due to simple combustion with hydrogen initially present $\left(2 \mathrm{H}_{2}+\mathrm{O}_{2}=2 \mathrm{H}_{2} \mathrm{O}\right)$. $\infty$ was usually simply added to $\infty_{2}$ to obtain a carbon inventory.

\section{Table 16 - Totals of Individual components}

Table 16 is really a series of tables, one for each component of the sample. Each summarizes the total amount and the contribution to the total present for each of several major sources. Oxygen is excluded from this tabulation. The sources are $\mathrm{O}_{2}-\mathrm{Air}, \mathrm{Ar}-\mathrm{Air}$, and Residual (or Cavity Gas). Each table is preceded by the standard header, which includes the reciprocal gas volume (including air) as defined in equation 1, and its percent uncertainty.

The gas to be summarized is then identified in the title lines of each of the several tables. The entries are:

TOTAL The total amount of the specific gas calculated from the initial sample concentration and the $(1 / F)$ values from equation 1, and listed in table 11.

$\mathrm{O}_{2}$-AIR The amount of the specific gas subtracted in the air correction based on $\mathrm{O}_{2}$. This value is the TOTAL AIR listed in table 13 times the specific gas abundance in normal air.

AR-AIR The amount of the specific gas subtracted in the oxygen free air correction based on Ar. This value is the TOTAL AIR volume listed in table 15 times the specific gas abundance in oxygen free air (i.e. $O_{2}$ is $0.00 \%$, all other air components are $1 /(1-0.209 / 46)=1.265$ times normal atmospheric abundance). 
SOIL

This option was never implemented. We had some hope of identifying an environmental tracer for the contribution of soil gas to the cavity (e.g. $\mathrm{Rn}-222$, He-4). None of these were developed into useful indicators.

RESIDUAL The residual is the difference between the total amount of the specific gas and the amounts contributed by air and soil sources. It is also the total of the specific gas listed in table 15.

RES/TOT The ratio of the residual to the total of the specific gas being summarized. This is a figure of merit for the significance of the residual result.

Following the listing of contributions for each component are two check calculations. The first uses $\mathrm{Ar}$ as the air indicator, and should produce an identical answer for the resicual as that calculated above. The calculation is: 12. Total $x$ (Residual) $=\frac{\text { total tracer } \times([\mathrm{X}] \mathrm{s}-([\mathrm{Ar}] \mathrm{s} \times[\mathrm{X} / \mathrm{Ar}] \mathrm{a}))}{[\text { Tor }] \mathrm{s}-([\mathrm{Ar}] \mathrm{s} \times[\text { Tor } / \text { Ar }] \mathrm{a})}$

where $[X] s,[A r] s$, and [Tor]s are the concentrations of $X, A r$, and the tracer species in the sample, [X/Ar]a and [Tcr/Ar] a are the ratios of $X$ and the tracer to Ar in normal air, and the total tracer is the amount loaded plus any additional material from extraneous sources. Beneath the residual row the code prints out the percent uncertainties calculated from error estimates input with the data.

Subsequent entries in the first check calculation are the resiculal to total ratio (RES/TOT), the residual expressed as moles (22.414 liters/mole), and the components of variance due to the uncertainties in the concentration of the gas, tracer, and air composition which were used to obtain the percent uncertainty of the residual given above.

The second check calculation is identical to the first, except that $\mathrm{Ne}$ is used as the air indicator instead of Ar. The reciprocal device fraction (1/F) is recalculated according to equation 1 (with $\mathrm{Ne}$ in place of Ar), and the residuals are calculated according to equation 12 (with $\mathrm{Ne}$ in place of $\mathrm{Ar}$ ).

The two check calculations should agree if $\mathrm{Ar}$ and Ne are not fractionated (i.e. are present in the normal air ratio). If they do not agree, the Ne approximation should be preferred for the air correction of residual $\mathrm{He}-4$, and the Ar approximation should be used for the tracer and heavy gas air corrections. Disagreement should serve as a warning flag. It is likely that Ne-Ar fractionation is not unique in a sample, and that all of the gases may be fractionated. Use of an isotopic tracer is indicated, if possible for determination of the total of a species. Where an isotopic tracer isn't present, the data should be suspect. 
Several of the table 16 summaries can be quite useful in detecting and evaluating the extent of fractionation. In particular, the $\mathrm{Ne} / \mathrm{Ar}$ fractionation can be read directly from either the contribution to total Ar table using $\mathrm{Ne}$ as the air indicator or the converse. If $\mathrm{Kr}$ or Xe are not loaded as tracers, the tables also give a direct read of the extent of fractionation of these gases relative to both $\mathrm{Ar}$ and $\mathrm{Ne}$. If both are loaded, the residual Xe based on $\mathrm{Kr}$ tracer table (or the converse) when compared to the actual load gives a measure of tracer fractionation.

Fractionation can be of two (at least) forms. Tracers (loaded species) can fractionate curing transport to the sampling inlet (we have lots of good evidence that these species are initially well mixed in the cavity). This usually creates a fractionation pattern which is relatively rich in the lighter gases compared to the heavier. We frequently loaded both $\mathrm{Kr}$ and Xe tracers to identify this phenomenon. quantitation of Xe isotopes should use Xe tracer, and totals of $\mathrm{Kr}$ isotopes should use $\mathrm{Kr}$ tracer if this fractionation pattern is detected. Tables involving mix-matching of the gases, although calculated by DELPHI, should be ignored.

Air gases can be fractionated from each other independently from any tracer fractionation. The air fractionation pattern can either show enrichment or depletion of the lighter gases relative to the heavier, although enrichment of the heavier air gases seemed to be more prevalent. This would have the effect of underestimating the air correction of $\mathrm{Kr}$ or Xe tracers. This consideration was usually not significant due to the choice of tracer quantities loaded, and the small size of the air correction required. Ne/He fractionation was generally not detectable, arbl air corrections to He-4 based on Ne were considered to be reliable.

\section{Table 17 - Activities in DPM/Liter \\ and}

Table 18 - Activities in picocuries/ $\alpha$ after $O_{2}$ air subtraction

Several Plowshare experiments were conducted in the late 1960 s to evaluate the feasibility of stimulating the production of natural gas using muclear explosives. Air was not a constituent of the natural gas (i.e. known not to be present in the nuclear chimney), and could only be seen in the samples as a consequence of unwanted leakage. Furthermore, the Health Physicists needing the concentration data from our analyses preferred that the data be expressed in units of picocuries/oc. Table 18 was included in DEIPFII to convert the data to these more desirable (for this purpose) units, and to exclude inadvertent air inclusion from the reported data. In early versions of DELPHI only table 18 was output (Table 17 was added later as an intermediary). 
In later Plowshare applications external communication of radionuclide concentrations as DPM/Liter was desirable. Table 17 was added to DEIPFI for this purpose. Table 18 became a derivative output tahle based on the data of table 17. Both tables present radionuclide data as concentrations per unit volume of sample after air subtraction based on oxygen. The only difference between the tables is the conversion from DFY/Liter to picocuries/oc:

13. picocuries $/ \propto=$ DFy $/$ Liter $/ 2.22 \times 10^{3}$

The concentration data of tables 17 and 18 was based on the totals of the radionuclides determined using the tracer of choice for the module (table 2) and the total oxygen air free gas volume (table 13, equation 7). This portion of DEXPHI was written during the era when fission gases were imput in units of OY TH FIS/Liter and non-fission gases were given as counts per minute per Liter. Derivation of DFM (or picocuries) therefore required the use of an "absolute "K" factor". " $K$ " was defined as "fissions/count" at the time, and had to be supplemented with a conversion from counts to disintegrations. For our purposes, it is sufficient to think of the conversion constant as "fissions/DPM" or "CPM/DPM" for non-fission product gases. By convention, $K$ was usually given as the recijprocal of these values. By these definitions:

$$
\text { 14. } \begin{aligned}
& \mathrm{K}=1 / \text { (atoms/fission) (DPM/atom) } \\
& \mathrm{K}=1 / \text { (DPM/CPM) }
\end{aligned}
$$

for fission gases for non fission gases

The atoms/fission values are those given in Table 3 as OY TH AT/FIS. DPM/atom is simply the decay constant for the muclide. CPM/DPM is the counting efficiency. At the time it was usual for most non-fission product gases to be determined by internal proportional counting where CPM/DPM $=1$. (A notable exception is $\mathrm{Pn}-222$ where CPM/DFM $=1.82$ due to the registration of decays of daughter radionuclides as well as those of the $\mathrm{Rn}-222$ itself). The complete algorithm is then:

$$
\text { 15. } \mathrm{DPM} / \mathrm{L}=\frac{\mathrm{X}(\text { total })}{\mathrm{L}\left(\mathrm{no} \mathrm{O} \mathrm{O}_{2} \text { air }\right)} \times \frac{1}{\mathrm{~K}}
$$

Subsequent to the demise of Plowshare, DEIPHI and the gas data were extensively revised. In particular, DETPHI was modified to identify results from different counting techniques using the measurement key, which required extensive modification to the internal data arrays. Also, the data were converted to a common absolute (atoms/liter) basis. Without Plowshare to drive an update, the pointers in DEI PHI were corrupted, and the algorithms were never corrected to the new reporting basis. In later versions of DELPHI, therefore, these tables are nonsense, and should be ignored.

(Note: for the purist, the later DELPHI versions reference only internal proportional counting concentration data (measurement key $=2$ data in table 1), divide by the oxygen air corrected sample volume and 
by the $\mathrm{K}$ value. The result is (atoms/L)/( $\mathrm{L}$ no $\mathrm{O}_{2}$ air)/(CFM/DFM) for non-fission gases, and is usually zero (blank) for fission gases which normally were not determined by internal proportional counting. In any case, the results are meaningless.)

\section{Table 19. - Specific Activities of Isotopic Species}

Provision was made in DETPHI for the calculation of eighteen specific activity ratios in response to a desire to determine the extent of isotopic exchange reaction processes in the Plowshare gas stimulation experiments. This table was of particular use in evaluating changes in the specific activities of hydrogen, methane and other hydrocarbon gases both with regard to their tritium content and their C-14 content. Ratios of fission products to their stable rare gas counterparts were included for purposes of completeness.

The calculations involved a simple ratio of the imput radionuclide concentration and the concentration of the stable isotopic species or compound. No air corrections or other data manipulations were done. The output units are fissions or dpm per liter of isotopic species. In newer versions of DEIPHI the units are atoms per liter of isotopic species.

The algorithm for specific activity calculations is:

16. $\frac{\text { OY TH FIS }}{\mathrm{L} \text { (active gas) }}=\frac{\text { OY TH FIS } / \mathrm{L} \text { (sample) }}{\mathrm{L} \text { (active gas) } / \mathrm{L} \text { (sample) }}$ for fission products or:

and:

$$
\frac{D P M}{L(\text { active gas })}=\frac{D P M / L(\text { sample })}{L(\text { active gas }) / L(\text { sample })} \text { for non-fission products }
$$

$$
\frac{\text { atoms }}{\mathrm{L} \text { (active gas) }}=\frac{\text { atoms } / \mathrm{L} \text { (sample) }}{\mathrm{L} \text { (active gas)/L(sample) }} \text { for more recent DELPHIs }
$$

where OY TH FIS/L(sample), DFM/L (sample), and atams/L(sample) are radionuclide concentration imput data from Table 1. (Note: While the convention was to input CPM data for non-fission gases, these ratios involved only tritium, C-14, and argon-37, 39. All of these muclides were determined by internal proportional counting where the CPM/DFM ratio is unity.) The $\mathrm{L}$ (active gas)/L(sample) values are the mole fractions from mass spectrometric analysis data in table 10.

It is worth noting that the tritium specific activity ratios as defined above assume single labeling of hydrogen and the the hydrocarbon gases. Thus, the true atam ratio is dependent upon the number of hydrogen atoms in the compound. For example, $\mathrm{HT} / \mathrm{HH}=1 / 2$ $\left(\mathrm{CH}_{3} \mathrm{~T} / \mathrm{CH}_{4}\right)$ at the same $\mathrm{T} / \mathrm{H}$ ratio. Care should be exercised when comparing $\mathrm{T} / \mathrm{H}$ specific activities between compounds. Only single carbon containing molecules $\left(\infty, \infty_{2}\right.$, and $\left.\mathrm{H}_{4}\right)$ are represented in the table, so that direct comparison is a lowed. 
Ratios of fission product gases to kypton or xenon in the sample, and of argon-37 and argon-39 to argon in the sample include no correction for air dilution. In fact, their principal use is as a measure of air dilution. The actual cavity gas ratios (air corrected) for krypton or xenon isotopes are calculated in DERPAI only as a consequence of the determination of their totals in the gas, and then only when $\mathrm{Kr}$ andy or Xe were used as tracers.

As was the case for the preceding tables, the modifications to DEIPHI that took place after the demise of Plowshare corrupted the array pointers used in the calculation of specific activities. The output of more recent DELFHI versions appears limited to muclides measured by gamma spectrametry on separated fractions of the sample (measurement key $=3$ ). This eliminates $\mathrm{T}, \mathrm{Ar}-37,39$ and $\mathrm{C}-14$ entries and leaves only the $\mathrm{Kr}$ and $\mathrm{Xe}$ isotopic ratios. Thus, although the calculations are correctly done and output, the specific activity table in these "newer" printouts is of little use.

\section{Table 20. - Total Tritium Results}

This table presents a step by step calculation of the total residual tritium for those device tests in which $D_{2} O$ was loaded as a tracer. After printing an ID line for the test device, the code outputs the weight $(\mathrm{Kg})$ of $\mathrm{D}_{2} \mathrm{O}$ tracer loaded and its purity. On the same line is given a calculated result for the equivalent muber of molecules of $\mathrm{D}_{2}$ in the loaded tracer. The calculation allows for Deuterium exchange as follows:

$$
\text { 17. } D_{2}=\frac{\left.\left(D_{2} O\right) \text { load *f(D } 20\right) * 6.02252 \times 10^{26}}{\operatorname{MN}\left(D_{2} O\right) * f\left(D_{2} O\right)+\operatorname{MN}\left(H_{2} O\right) *\left(1-f\left(D_{2} O\right)\right.}
$$

where $D_{2}$ is the equivalent number of $D_{2}$ molecules corresponding to the amount and purity of the $D_{2} O$ loaded, $\left(D_{2} O\right)$ load is the weight of the heavy water loaded (in $\mathrm{Kg}$ ), $f\left(D_{2} \mathrm{O}\right.$ ) is the mole fraction of $D_{2} O$ in the loaded material, $M N\left(D_{2} O\right)$ is the molecular weight of $D_{2} O$ $(20.0296 \mathrm{~g} / \mathrm{mole})$, and $\mathrm{MW}\left(\mathrm{H}_{2} \mathrm{O}\right)$ is the molecular weight of $\mathrm{H}_{2} \mathrm{O}^{2}$ $(18.01505 \mathrm{~g} / \mathrm{mole})$. The constant is Avagadro's number augmented by the conversion fram kilograms to grams.

The second line is purely information. It states that the measured $\mathrm{D}_{3} / \mathrm{H}_{2}$ data have been corrected by a factor that adjusts the standard Hetch Hetchy water run with the samples to $144 \mathrm{ppm}$. The D/H ratio was measured in hydrogen from the sample using a specially tuned mass spectrometer. (After fine tuning the instrument, the sample was run at several pressures. The $\mathrm{D} / \mathrm{H}$ value reported was the result when these data were extrapolated to zero pressure.) The correction factor was based on a sample of hydrogen prepared from water taken from the Hetch Hetchy reservoir in the Sierras, and run at the same time as the samples. 
The correction factor was applied to all samples measured in that analysis, and is simply:

18. $f(c o r)=144 /(D / H)$ msd-std

where $f(\infty)$ is a multiplicative correction that was applied to all measured $\mathrm{D} / \mathrm{H}$ ratios, and $(\mathrm{D} / \mathrm{H})$ msd-std is the measured ratio in the standard. (D/H) msd-std and $f(c o r)$ are output on the last two lines of the main table as ( $D_{2}$ STND VAUEE USED) and ( $D_{2}$ NORM VAUUE USED), respectively.

The thind line of the table gives the background $\mathrm{D}_{2} / \mathrm{H}_{2}$ in the shot medium that was used in the calculations. Early versions of DEIPFII were capable (an option) of iterating this value. These printouts contain a series of tritium results tables, one for each value of the background $D_{2} / H_{2}$ used. A summary of the 25 step iteration process followed the series of tables. Later versions of DEIPHI "lost" this capability and simply used the default value of 148 ppm. to generate a single table. When samples were of good quality, and iteration was possible, the minimum standard deviation of the average was typically seen at $100+/-20 \mathrm{ppm}$. Use of $148 \mathrm{ppm}$ was often acceptable, although incorrect, because of the small size of the background contribution as compared to the amount of $D_{2} \mathrm{O}$ loaded.

The next three lines of the tritium results summary constitute the standard header information for the samples. Following the header are the measured quantities used in the calculation. The line labeled "DPM T PER L SAMPLE" is the tritiated hydrogen comentration in the sample. This was measured by internal proportional counting (Measurement key = 2) of separated hydrogen. Its percent uncertainty is given on the next line. These data are taken from table 1 (which is in atoms/L) and converted to DFM/L by multiplying by the tritium decay constant $\left(1.0671 * 10^{-7} / \mathrm{min}\right.$.). In earlier versions of DEIPHI this conversion was unnecessary, as the data were imput as DPM/L. This conversion was addied when our reporting base changed to ATOMS/L as an expedient (the data is converted back to ATOMS/L later in the table). The next line labeled "MEASURED $\mathrm{D}_{2} / \mathrm{H}_{2}$ " is the $\mathrm{D} / \mathrm{H}$ ratio determined by mass spectrometry. Beneath the ratio is its percent standard deviation. These data are identical to the input data contained in table 8 . The main body of the table follows, and is a step by step derivation of the residual tritium total for each sample. The results of each step of the calculation are listed, row by row. The steps are:

$$
\text { 19. }\left(\mathrm{CC} \mathrm{H} \mathrm{H}_{2} / \mathrm{L} \text { SAMPLE }\right)=\left[\mathrm{H}_{2}\right] \mathrm{s} * 10^{3}
$$

where $\left[\mathrm{H}_{2}\right] \mathrm{s}$ is the measured mole fraction of hydrogen in the sample (table 8). 


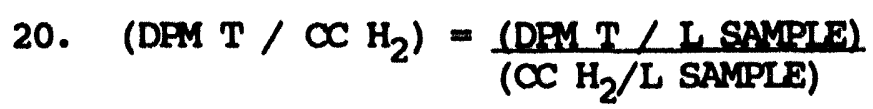

where (DPM T / L SAMPLE) is the converted imput concentration of tritiated hydrogen, and $\left(\mathrm{CC} \mathrm{H}_{2} / \mathrm{L}\right.$ SAMIPIE) is the result of equation 19.

21. (ATONS $\left.T / \propto \mathrm{H}_{2}\right)=\left(\mathrm{DPN} \mathrm{T} / \propto C \mathrm{H}_{2} \perp /\left(1.0671 * 10^{-7}\right)\right.$

where (DFM T / $\propto \mathrm{H}_{2}$ ) is the result of equation 20, and the constant is the decay constant for tritium (per min.).

22. $\left(\propto D_{2} / \propto \mathrm{H}_{2}\right)=$ (MEASURED $\left.D_{2} / \mathrm{H}_{2}\right) * f(\infty)$

where (MEASURED $\mathrm{D}_{2} / \mathrm{H}_{2}$ ) is the imput $\mathrm{D} / \mathrm{H}$ ratio listed above, and $f(c o r)$ is the correction factor necessary to correct the Hetch Hetchy standard to 144 ppm. (equation 18).

23. (MOLECLS $D_{2}$ PER $\left.\propto \mathrm{H}_{2}\right)=\left(\left(\propto \mathrm{D}_{2} / \propto \mathrm{H}_{2}\right)-\right.$ BKG $\left.\mathrm{D} / \mathrm{H}\right) * \mathrm{~K}$

where the derived quantity is molecules $\mathrm{D}_{2}$ per $\propto \mathrm{H}_{2}$, the term $\left(\subset D_{2} / \propto \mathrm{H}_{2}\right)$ is the result of equation 22, and $B K G \mathrm{D} / \mathrm{H}$ is the adopted value for the $\mathrm{D} / \mathrm{H}$ ratio of the detonation environment (acoording to the iteration, or $148 \mathrm{ppm}$ by default). The constant, $\mathrm{K}$, is $6.02252 * 10^{23} / 22414$.

\section{4. (ATOMS $\mathrm{T} /$ MOLECL $\mathrm{D}_{2}$ ) $=\frac{\left.\text { (ATOMS } \mathrm{T} / C C \mathrm{H}_{2}\right)}{\left(\text { MOLECTS } \mathrm{D}_{2} \text { PER } O C \mathrm{H}_{2} \text { ) }\right.}$}

where the derived quantity is atoms of tritium per (net) molecule of deuterium $\left(D_{2}\right)$, (ATOMs $T / C \mathrm{H}_{2}$ ) is the result of equation 21 , and (MOLECTS $\mathrm{D}_{2}$ PER $\propto \mathrm{CH}_{2}$ ) is the result of equation 23 .

$$
\text { 25. TOTAL } \left.T \text { (ATOMS) }=\text { (ATONS } T / \text { MOLECL } \mathrm{n}_{2}\right) * D_{2}
$$

where (ATOMS $T /$ MOLECL $D_{2}$ ) is the result of equation 24 , and $D_{2}$ is the equivalent number of $\mathrm{B}_{2}$ molecules loaded from equation 17.

26. TOTAL $\mathrm{T}$ (MOLES) $=$ TOTAL $\mathrm{T}$ (ATOMS) $/ 6.02252 * 10^{23}$

where TOTAL T (ATOMS) is the result of equation 25, and the constant is Avagadro's Number.

27. TOTAL $T$ (GRAMS) = TOTAL $T$ (MOLES) $* 3.01605$

where TOTAL T (MOLES) is the result of equation 26, and the constant is the atamic weight of tritium. The next line of the printout is the percent standard error applicable to all of the TOTAL $T$ results. 
28. (KILOTONS $\mathrm{H}_{2} \mathrm{O}$ EQUTV) $=\frac{\mathrm{D}_{2} * 1.801505 * 10^{-8}}{\left(\text { MOLECTS } \mathrm{D}_{2} \mathrm{PER} \propto \mathrm{CH} \mathrm{H}_{2}\right) * 22414}$

where $D_{2}$ is the equivalent number of $D_{2}$ molecules loaded from equation 17, and (MOLDCLS $D_{2}$ PER $\propto \mathrm{H}_{2}$ ) is molecules $\mathrm{D}_{2}$ per $\propto$ $\mathrm{H}_{2}$ calculated in equation 23 . The constants are (18.01505 $\left.\mathrm{g} / \mathrm{mole} \mathrm{H}_{2} \mathrm{O}\right) /\left(10^{9} \mathrm{~g} / \mathrm{Kt}\right.$ ) and $22414 \propto \mathrm{H}_{2}$ per mole.

29. (HT/TOTAL TRITIUM) $=$ (TOTAL HT) / TOTAL $T$ (ATONS)

where the (TOIAL HT) is obtained from table 2, and the TOTAL T (Atoms) is calculated by equation 25.

The last two lines of the results tabulation are the measured $D / H$ ratio in the Hetch Hetchy water standard (D2 STND VAUUE USED) and the normalization factor ( $D_{2}$ NORM FACTOR USED) applied to the sample $\mathrm{D}_{2} / \mathrm{H}_{2}$ measurements ( $\mathrm{f}(\mathrm{COr})$ from equation 18 ).

A series of average values is given below the tritium results table. The first summary line gives a straight average of the total residual tritium results in units of grams, moles and atams along with the percent standard deviation of a measurement for these averages.

On the second line of the summary, the average grams of total residual tritium from an inverse variance weighting of the results is given, along with the percent standard deyiation of a measurement from the weighted averaging. The value of $\mathrm{CHI}^{2}$ for the weighted average is also given, as is the number of degrees of freedom for the determination.

The third line is included for comparison with the secord. It contains the unweighted average residual tritium result, the percent standard deviation of a measurement, and the $\mathrm{CHI}^{2}$ value for this determination. The average and standard deviation are the same mumbers which appear on the first summary line, with an additional significant figure.

DEIFHI then begins culling the data by dropping samples with results that are more than a factor of 1.15 (older versions used a factor of 1.2) away fran the mean. If one or more such samples are found, the number of the sample with the largest deviation from the mean and the factor by which it deviated are printed and that sample is subsequently excluded from the averaging algorithm. Then the weighted and unweighted averages (grams residual) for the remaining samples are computed. The output is a reiteration of that described for lines 2 and 3 of the summary in the preceding paragraph, except that the deviant sample is omitted. DELPHI then checks the remaining samples against the new average value using the 1.15 factor as its deviation criterion, eliminates the one with the largest deviation, and repeats the averaging process for the remaining samples. When no samples are more than a factor of 1.15 from the mean, DEIPFII calls a stop to the calculations. 
If the version of DEIPHI is an old one, and if the iteration option was "on", then a series of up to 26 tables of the sort described above will be present in the output (corresponding to background $\mathrm{D} / \mathrm{H}$ values from 40 to $165 \mathrm{ppm}$ in steps of $5 \mathrm{ppm})$. If the unweighted chi-square values for this series of calculations continued to either increase or decrease as the background was increased by steps, DETPFI would call a stop to the calculations after reaching $165 \mathrm{ppm}$. If a minimum was encountered in the unweighted chi-square values, DEIPHI would interpolate within the $5 \mathrm{pgm}$ range to find the background $\mathrm{D} / \mathrm{H}$ value corresponding to the minimm chi-square and use this value to calculate the residual tritium. As a "proof of concept", DEIPHI also calculated residual tritium based on the best background value plus 1 and minus 1 ppm. After outing these calculations, DEIPFI would call a halt to the calculations. No computations using higher values for the $D / H$ background were done after the minimm was obtained.

The final output page in the residual tritium tabulation is a summary of the resuits of the iterations. A statement of the number of iterations required to locate a minimm in the unweighted chi-square vlaues precedes the tabulation. If no minimm is found the iteration would stop after 25 trials.

The table is ordered by the background $\mathrm{D} / \mathrm{H}$ value used. column headings, in order, are: GRAMS T, WIDSE, CHI2, POTS, DBKGD, UNWID, STD DEV, AND CHI2. The first three columns are the weighted average residual tritium, the weighted standard deviation of a measurement and the $\mathrm{CHI}^{2}$ value for the weighted average. The column "Pors" lists the number of samples included in the final average (after culling has removed all samples deviating from the average by more than a factor of 1.15). the column titled "DBKGD" is the background $\mathrm{D} / \mathrm{H}$ ratio used to calculate the other entries on that line. The last three oolumus are the unweighted average, its standard deviation, and its $\mathrm{cHr}^{2}$ value. 

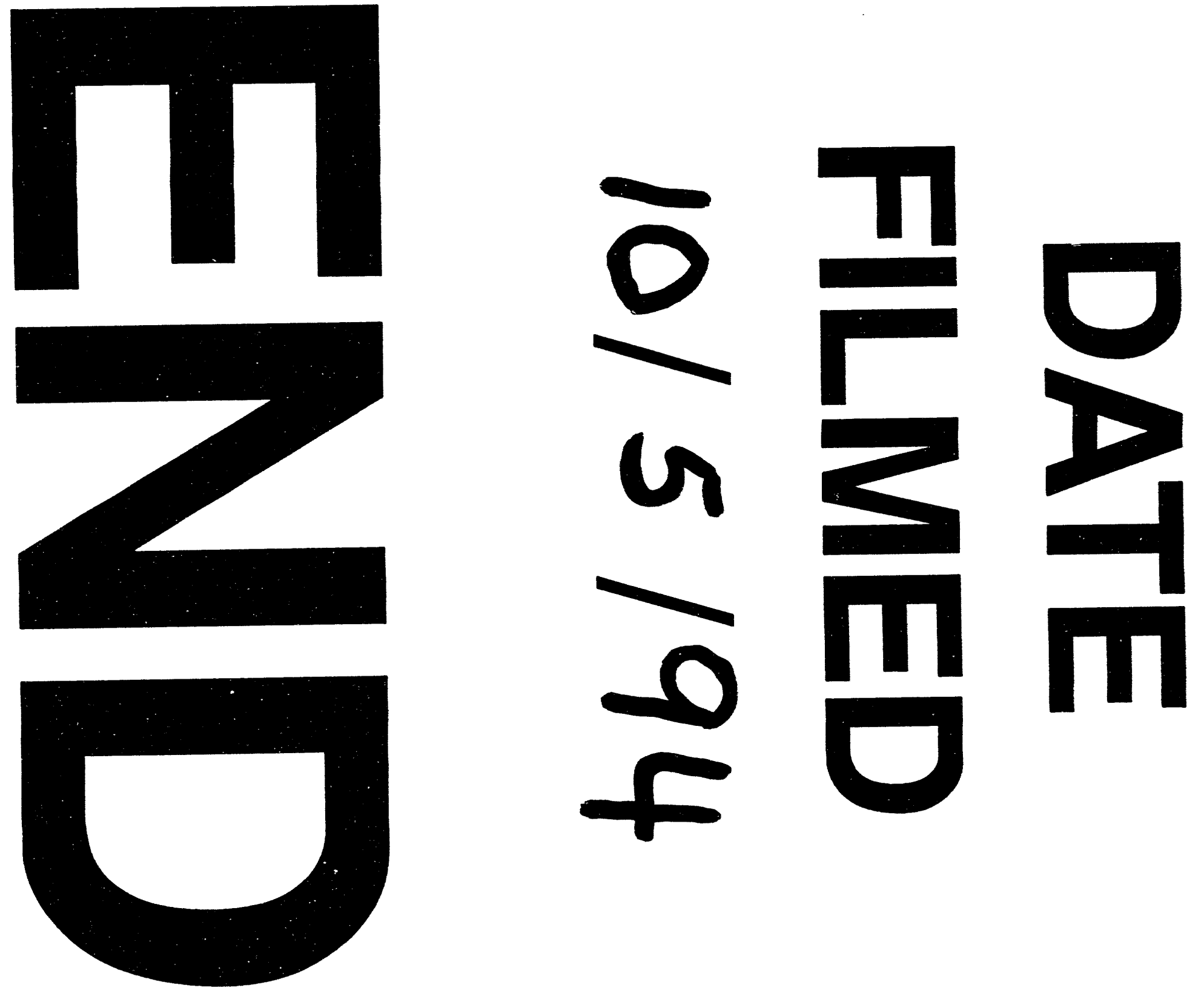